\title{
Joint Multi-item Multi-supplier Sustainable Lot- sizing Model Applying Combined BWM, TOPSIS, Possibilistic Programming, and $\varepsilon$-constraint Method
}

\section{Krishnendu Shaw}

IIT (ISM): Indian Institute of Technology

Vijay Lahri ( $\square$ vijay.lahri07@gmail.com )

IIT (ISM): Indian Institute of Technology

\section{Ravi Shankar}

IIT Delhi: Indian Institute of Technology Delhi

\section{Research Article}

Keywords: lot-sizing, Best-Worst method, TOPSIS, $\varepsilon$-constraint, social sustainability, carbon footprint, solid waste, liquid waste, recycled materials, possibilistic programming

Posted Date: February 24th, 2021

DOI: https://doi.org/10.21203/rs.3.rs-232413/v1

License: (9) This work is licensed under a Creative Commons Attribution 4.0 International License. Read Full License 
Dear Editor (s),

We have the pleasure of sending you the manuscript entitled "Joint Multi-item multi-supplier sustainable lot-sizing model applying combined BWM, TOPSIS, Possibilistic Programming, and E-constraint method" to be considered for publication as a regular research article in your reputed journal- Clean Technologies and Environmental Policy.

We accept the conditions of submission and journal copyright. We confirm that this work is original and has not been published or accepted elsewhere apart from Clean Technologies and Environmental Policy. We will be happy to incorporate the necessary changes suggested by distinguished reviewers. We would appreciate it if you could communicate and acknowledge the receipt of this communication. Hope to hear from you soon.

We are thanking you in anticipation.

Author (s) and their affiliation:

Krishnendu Shaw ${ }^{\mathrm{a}}$, Vijay Lahri ${ }^{\mathrm{a}^{*}}$, Ravi Shankar ${ }^{\mathrm{b}}$

aDepartment of Management Studies, Indian Institute of Technology (ISM) Dhanbad, Jharkhand- 826004, India

${ }^{b}$ Department of Management Studies, Vishwakarma Building, Indian Institute of Technology Delhi, New Delhi 110016, India

Regards,

Vijay Lahri*(corresponding author)

Research scholar, Department of Management Studies

Indian Institute of Technology (ISM)

Dhanbad, Jharkhand- 826004, India

Email: vijay.lahri07@gmail.com

Contact: +91-8765756062 


\title{
Joint Multi-item multi-supplier sustainable lot-sizing model applying combined BWM, TOPSIS, Possibilistic Programming, and \&-constraint method
}

\author{
Krishnendu Shaw ${ }^{\mathrm{a}}$, Vijay Lahri* ${ }^{\mathrm{a}}$, Ravi Shankar ${ }^{\mathrm{b}}$ \\ ${ }^{a}$ Department of Management Studies, Indian Institute of Technology (ISM) Dhanbad, Dhanbad, Jharkhand- \\ 826004, India
}

${ }^{b}$ Department of Management Studies, Vishwakarma Building, Indian Institute of Technology Delhi, New Delhi 110016, India

Vijay Lahri*(corresponding author)

Research scholar, Department of Management Studies

Indian Institute of Technology (ISM)

Dhanbad, Jharkhand- 826004, India

Email: vijay.lahri07@gmail.com

Contact: +91-8765756062

\begin{abstract}
Procurement decisions play a vital part in the sustainable transformation of the supply chain. Till now, a variety of supplier selection and lot-sizing models have been suggested, in particular, focusing on carbon emissions in a deterministic environment. It is noted that stressing only on carbon emissions cannot fully transform a sustainable supply chain. The present study argues that with carbon footprint, other dimensions, such as social sustainability, water footprint, recycled material use, solid and liquid waste, need to be considered in sustainable procurement decisions. To fill the gaps, this study proposed a threestage multi-objective multi-supplier, multi-period joint supplier selection, and a lot-sizing model, taking into account carbon footprint, water footprint, solid and liquid waste, and use of recycled materials in a stochastic environment. The model optimizes three objectives (cost, carbon emission, and social sustainability). The model considers different model parameters as uncertain, such as costs, emission, solid waste, liquid waste, recycled material, quality rejection, and capacity. The present study suggests how to quantify social sustainability and further use it in the lot-sizing model. The proposed study has been carried out in three stages. In the first stage, BWM (Best-Worst method) and TOPSIS are applied to evaluate suppliers' social scores. In the second stage, the suppliers' social scores are used in the proposed possibilistic lot-sizing model. In the third stage, various trade-off curves are generated by applying the $\varepsilon$ constraint method. The model produces distinct optimal solutions for different uncertainty levels, which are used to create trade-off curves among the cost, emission, and social dimensions. The results facilitate decision-makers to decide the lot-size in an ambiguous environment.
\end{abstract}




\section{Graphical abstract}

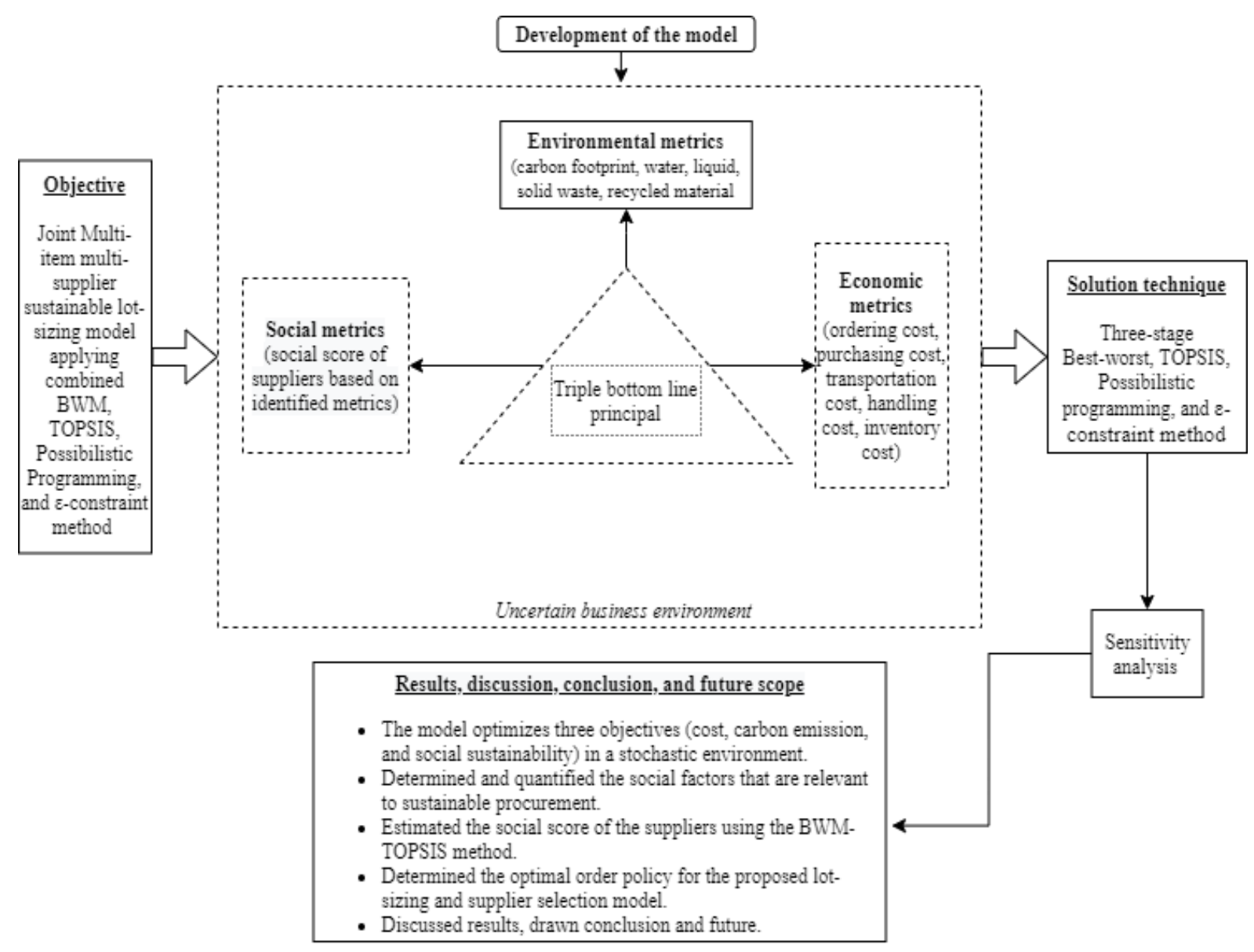

Keywords: lot-sizing; Best-Worst method; TOPSIS; $\varepsilon$-constraint; social sustainability; carbon footprint; solid waste; liquid waste; recycled materials; possibilistic programming. 


\section{Introduction}

Procurement decision in the supply chain is a challenging activity that draws significant attention from researchers and decision-makers (Kaur and Singh 2017). It has considerable importance for operational decisions because a substantial amount of costs are incurred in procurement. As per the findings of De Boer et al. (2001), the procurement costs can reach up to 60 percent of the finished product cost. Nowadays, procurement is no longer a clerical activity; it is a strategic tool of competitive advantage. In the era of globalization, sustainable development has received significant attention from various governments and policymakers. A sustainable supply chain is a tactical competence that facilitates firms to remain competitive in today's marketplace. The need to develop a sustainable supply chain is relevant in recent times because many governments worldwide are implementing stringent rules to reduce carbon emissions and avoid the social exploitation of the employees (Sikdar 2007; Sharma et al. 2020). Besides, consumers also prefer to buy green and socially sustainable products (Pathak et al. 2020). Implementing sustainability in the supply chain is a complex and multi-dimensional problem. Joint lotsizing and supplier selection have significant potential to minimize the environmental footprint and manage a supply chain's social sustainability. Recently, Benjaafar et al. (2012) and Bonney and Jaber (2011) argued that the modification of the operational policy could cut the environmental footprint of a supply chain. Till now, most of the studies have dealt with the lot-sizing problem from an economic and inventory control perspective. However, there is a need to study the lot-sizing problem from the triple bottom line's perspective to mitigate the environmental and social risks of the supply chain. In literature, a significant amount of studies have been conducted addressing the economic dimension, solvability of the model in-finite time. For example, Robinson et al. (2009) compared the performance of different algorithms in a deterministic environment. Cárdenas-Barrón et al. (2015) introduced an innovative heuristic algorithm to solve the multi-product multi-period lot-sizing and supplier selection problem. The demand and price uncertainty were studied by Şenyiğit and Erol (2010) in multiperiod single-item settings. Alfares and Turnadi (2018) proposed a MIP model for supplier selection and lot-sizing problem, taking into account quantity discounts and back-ordering of shortages. Fan et al. (2018) examined the dynamic joint lot-sizing problem for a single product under warehouse capacity constraint. They considered fixed ordering cost and linear holding cost and solved the model using an O(T4) dynamic programming algorithm. Büyüktahtakın et al. (2018) analyzed the single level, multi-item capacitated lot-sizing problem under partial objective inequalities. Zhou et al. (2018) investigated multi-item lot-sizing problems under capacity constraints and time-varying environment. Kirschstein and Meisel (2019) developed joint supplier selection and lot-sizing problem considering multi-item, multi-commodity, and multi-period. They have explored quantity discounts in 
their model. Gruson et al. (2019) compared 13 Mixed integer programming models for three-level lot-sizing and replenishment problems. Slama et al. (2020) investigated the disassembly problem in lot-sizing to mitigate environmental concerns. They also consider the multi-period capacitated problem with backlogging, external procurement, defective parts, and setup times in a dynamic environment. Capacitated lot-sizing is a very vast and exciting research problem in management science. Unfortunately, little importance was paid to the sustainable lot-sizing problem. As of now, a significant emphasis was given to quantify carbon footprint for the lot-sizing problem. Unfortunately, little emphasis was paid to water footprint, solid and liquid waste, and recycled material usage for the lot-sizing problem. The research was also limited in addressing the uncertain cost, quality rejection, and capacity. The authors could not find a single paper addressing all the aforesaid factors. In order to fill the gaps of existing research, this paper intends to develop a multi-item, multi-supplied, lot-sizing model, taking into account social sustainability, carbon emissions, water footprint, solid and liquid waste, recycled material use, under uncertain capacity, uncertain quality rejection and uncertain costs. The present study intends to answer the following research questions.

Research questions:

What are the factors that are relevant to sustainable lot-sizing?

Which sustainability factors should be considered for procurement?

How to quantify the social score of the suppliers?

How can the social score be incorporated into the mathematical lot-sizing model?

How to handle the uncertainties of the model parameters?

What are the relationships among the conflicting goals for procurement?

What is the optimal ordering policy for the supplier?

The current study has been conducted in three stages. The suppliers' social scores are calculated employing the combined BWM and TOPSIS method in the initial stage. Further, the social scores of the suppliers are used in the lot-sizing model. In the third stage, various trade-off curves are generated by applying the e-constraint method. The efficacy of the model has been illustrated with a numerical example.

The rest of the research work is organized as follows. Section 2 explores the literature associated with general lot-sizing, dual sourcing, and carbon-constrained lot-sizing. Section 3 discusses the background of the problem and the suggested solution methodology. In section 4 , the proposed model is illustrated through a numerical example, and the results are discussed. Section 5 concludes the findings of the study. 


\section{Literature review}

In this section, we discuss the relevant literature related to multi-item capacitated lot sizing and relevant issues. Lot sizing is an evergreen research topic in management science. The fundamental inventory management model is EOQ, proposed by Harris in the year 1920 (Harris 1913). Interestingly, it remains equally relevant as it was in the 1920 s due to its cost reduction capability. A considerable theoretical enrichment of inventory management theory was taken place between the 1950s to 1960s due to some classical studies of Whitin (1953), Arrow et al. (1962), and Hadley and Whitin (1963). The dynamic lot-sizing model was based on the study of Wagner and Whitin (1958). Subsequently, the capacitated lot-sizing problem has been extended in various directions. Various authors conducted a comprehensive review on lot-sizing, for example, Maes and Van wassenhove (1988); Drexl and Kimms (1997); Karimi et al. (2003); Aissaoui et al. (2007); Quadt and Kuhn (2008); Jans and Degraeve (2007); Ben-Daya et al. (2008); and Robinson et al. (2009). Different researchers reported the computation time for lot-sizing problems (Brahimi et al. (2006); Önal and Romeijn (2009); Wu and Shi (2011). Many studies combined the lot-sizing problem with supplier selection (Ustun and Demirtas, 2008; Demirtas and Ustun, 2009; Razmi and Maghool, 2010; Rezaei and Davoodi, 2011). Sancak and Salman (2011) and Norden and van-de-Velde (2005) addressed the delayed transportation policy and transportation capacity reservation contract in a lot-sizing model, respectively. Choudhary and Shankar (2011) proposed a linear programming-based lot-sizing model for single products, single suppliers considering price discount, late delivery, and rejection. Brandimarte (2006) formulated a multi-item capacitated lot-sizing problem considering demand uncertainty. Their study used a scenario tree to represent uncertainty. Şenyiğit and Erol (2010) addressed demand and price uncertainty for a lotsizing problem taking consideration of service level. The authors extended silver meal heuristics, the least unit cost heuristics, and came up with cost-benefit heuristics to cope with rolling demand and price uncertainty. In recent literature, researchers have stressed the uncertainty issue in the capacitated lot-sizing problem. For example, Mohammadi et al. (2020) introduced MILP based lot-sizing problem in an uncertain environment. They consider stochastic demand, multiple modes, and discount levels in the model. Chance-constrained programming was applied to solve the model. Quezada et al. (2020) discussed the uncapacitated lot-sizing problem considering multi-product, multi-echelon (i.e., disassembly, refurbishing, reassembly) in an uncertain environment. Attila et al. (2020) extended the lot-sizing model considering remanufacturing and backlogging.

\section{1 lot-sizing considering environmental aspects}

All the above studies have focused on lot-sizing and outsourcing issues from an economic perspective. Benjaafar 
et al. (2012) developed an innovative linear programming-based single product lot-sizing model considering the carbon emission issue. They have incorporated fixed ordering cost, variable cost, inventory holding cost, carbon emission tax, carbon cap, holding emissions in their model. Bonney and Jaber (2011) questioned the conventional inventory management theory and advocated incorporating the environmental factors in the traditional model. Hua et al. (2011) extended the EOQ model by incorporating emission trading, cap and trade. They observed that the minimization of carbon emission for ordering policy increases the total cost. They provided various strategies for the retailer to survive in a carbon-constrained world. The analytical examples are complementary to the Benjafaar (2010) study. A similar type of research was conducted by Chen et al. (2011). Arslan and Turkay (2011) further extended the EOQ model by considering carbon emission and working hours into it. They explored the four regulatory policies which were studied by Benjafaar (2010). Absi et al. (2016) applied a periodic carbon emission constraint in the lot-sizing problem. Wu et al. (2018) introduced carbon emission constraints in multiitem lot-sizing problem. They applied the Lagrangian relaxation and column generation method to solve the lotsizing problem. Lamba et al. (2019) suggested a multi-item capacitated lot-sizing model under a big data environment. Various scenarios were explored under the carbon cap and trade. Phouratsamay and Cheng (2019) investigated the lot-sizing problem under strict carbon cap and trade policy for each period. They demonstrated that the carbon cap and trade could impact the firm's environmental sustainability. Vaez et al. (2019) proposed a bi-objective lot-sizing and scheduling model considering economic and environmental sustainability. They have applied the $\varepsilon$-constraint method to draw an optimal trade-off between the multi-objective. Surprisingly, none of the above studies have considered the triple bottle line principle for the lot-sizing problem.

\subsection{Importance of social sustainability for lot-sizing}

Social sustainability is an essential pillar of the 21 st Century business environment. High social sustainability portrays a better image of an organization in the global market and affects workforce productivity (Sikdar et al. 2017; Liu and Stephens 2019). Although social sustainability is an integral part of a business, as of now, it is being handled at the lowest priority for ordering policy (Staniškienè 2018). The importance of social sustainability for the supply chain has been illustrated in studies of Das and Shaw (2017) and Das et al. (2020). Suppliers can be viewed as the backbone of the original equipment manufacturer (OEM). Hence, any social discrepancy at the supplier level can propagate in the whole supply chain. It can negatively affect the consumers and create a bad image for the OEM (Bai et al. 2019). Till now, different mathematical models were reported on supplier selection, considering the environment and economic aspects. Unfortunately, very few studies have been done focusing on 
the social part of suppliers (Mani et al. 2014).

\subsection{Importance of water footprint, recycled material used, solid and liquid waste for lot sizing}

Water footprint has become a significant concern factor for most of the production processes. The freshwater is diminishing faster, which can create severe water scarcity in the coming years (Sikdar et al. 2017). Hence, water needs to be consumed very cautiously for producing goods and services. The water footprint is the total amount of direct and indirect freshwater consumed and polluted (Cucek et al. 2012). Heck and Schmidt (2010) adopted the power cost, carbon emission costs, and water usage costs for developing the lot-sizing problem. Kantas et al. (2015) introduced the water footprint in the lot-sizing problem of biofuel production. The authors used a water usage cap for ethanol production. Water footprint has been taken in the supply chain network design in a recent study by Das et al. (2020). The literature review shows that lot-sizing considering water footprint has not been studied well in the archived literature. Solid and liquid wastes are two essential factors for selecting sustainable suppliers. After searching the literature, we could not find the direct lot-sizing papers addressing solid and liquid waste. However, there are studies on the topic of supplier selection problem mentioning solid and liquid waste. For example, Humphreys et al. (2006) introduced liquid waste factors for selecting the suppliers.

Similarly, Humphreys et al. (2003) suggested solid waste for selecting the suppliers. Chiou et al. (2011) introduced environmental waste for supplier selection. Recycling material use is another pressing issue for implementing sustainability. Initially, Min and Galle (1997) suggested the importance of recycled material for the supplier selection problem. Similarly, Govindan and Sivakumar (2016) addressed the recycled material used for supplier selection. The relevant studies are summarized in Table 1.

Table.1 Literature review related to supplier selection and lot sizing

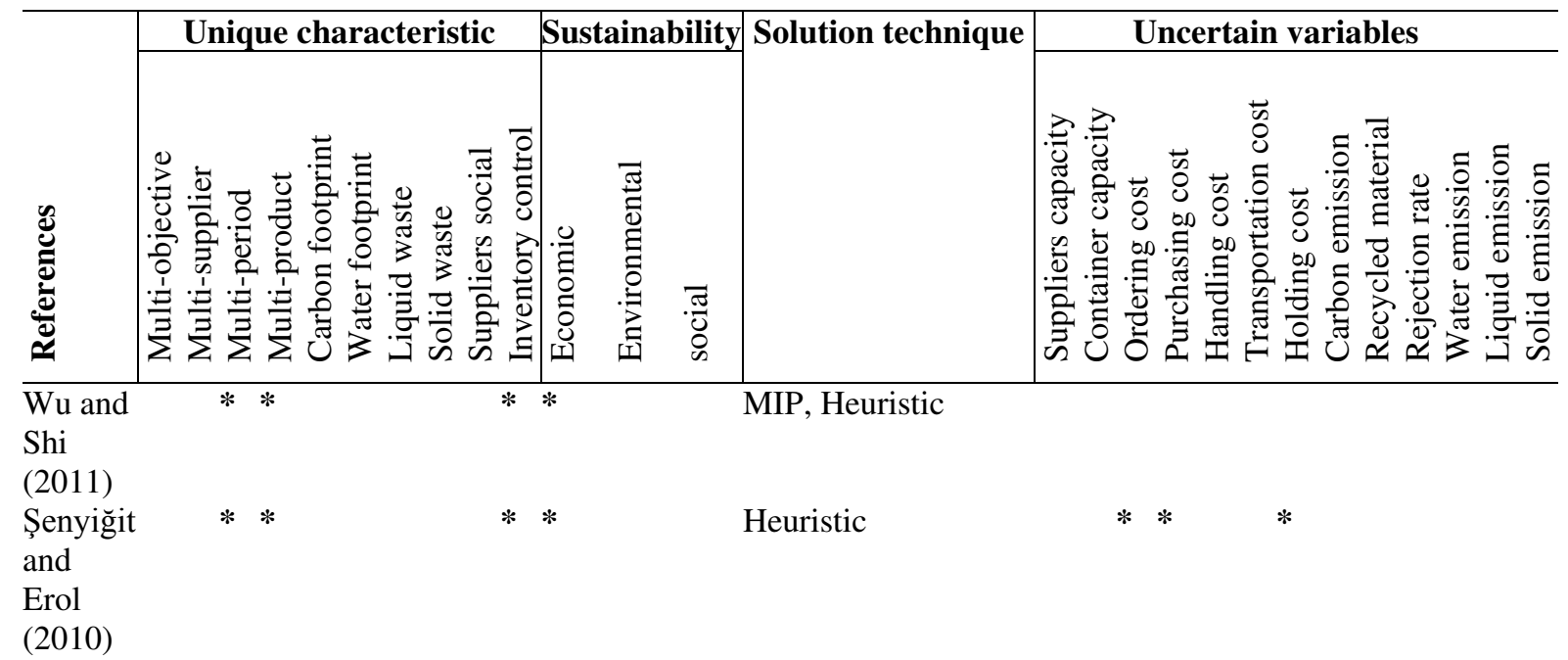




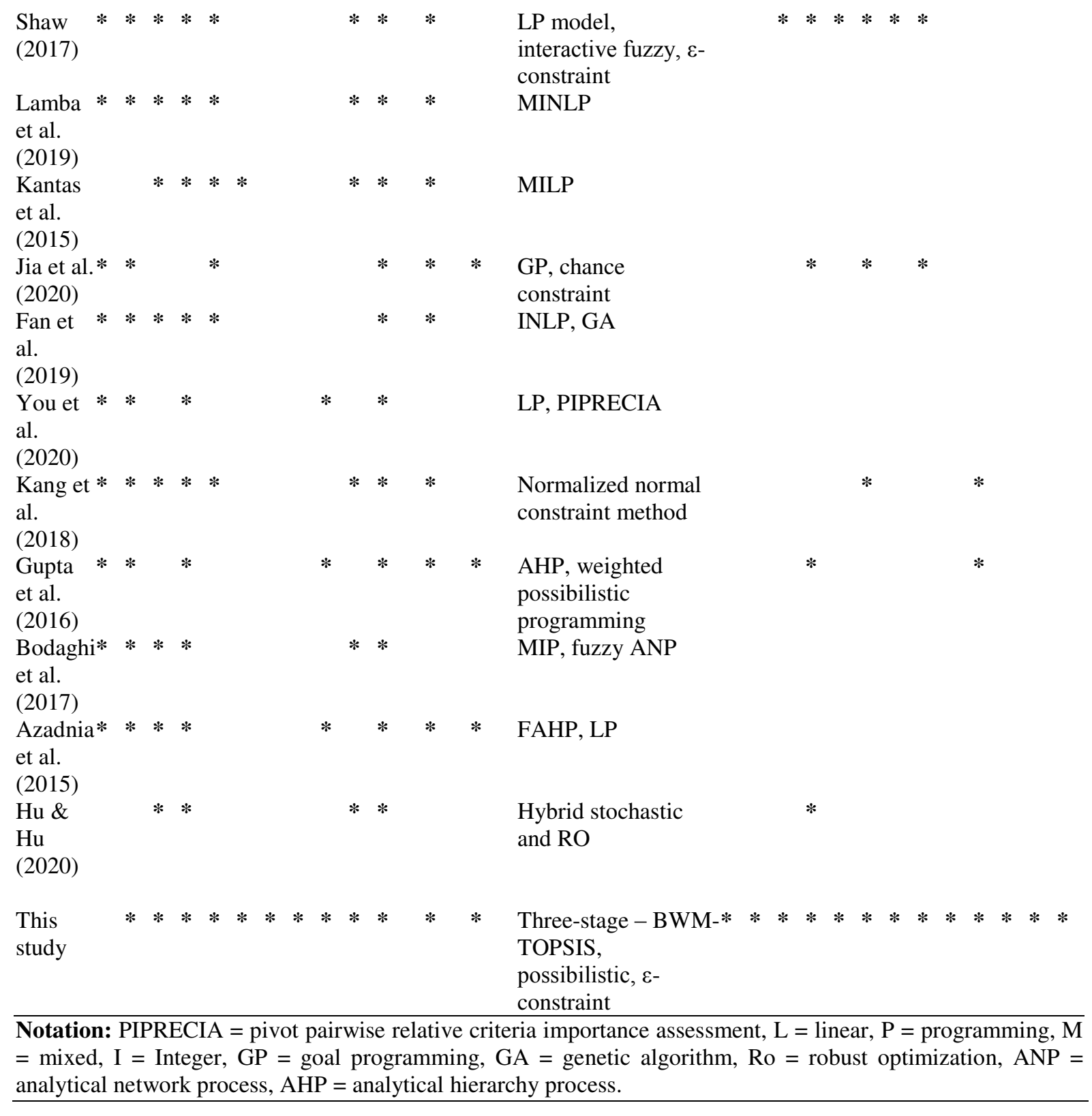




\subsection{Research gaps}

The earlier lot-sizing studies mostly addressed the cost minimization, various heuristics to get the right solution in a finite time, service level, and various related issues. Few studies address the carbon emission issue for lot-sizing. However, few lot-sizing models have been reported considering multi-item, multisupplier with uncertain factors (like costs, capacity, emission, water footprint, social sustainability, solid waste, liquid waste, recycled material use, and quality) simultaneously. In addition, limited studies have been carried out by applying combined BWM, TOPSIS, possibilistic programming, and $\varepsilon$-constrained method to handle the lot-sizing problem. In the archived literature, a significant emphasis is given to carbon emission, ignoring other environmental factors (such as water footprint, solid waste, liquid waste, recycled material use) and social factors. Literature is limited in addressing quantifying the social score and incorporation of the scores in the lot-sizing model.

\section{Model development}

In this section, we propose a sustainable lot-sizing model considering the dimensions of the triple bottom line. The considered manufacture produces different products to satisfy the demand of the customers at different points of time. To fulfill the demands, the manufacturer procures materials from multiple suppliers. The decision-maker requires estimating the lot-size of the procurement at different points of time. The procurement decision is subjected to various constraints like capacity, cost, inventory holding cost, and transportation cost. Previously, the company was given more emphasis on the economic aspects for sourcing. Recently, the company's management wants to relook its sourcing strategy due to an increase of consciousness of the customers' environmental and social consciousness. The management seeks to improve the environmental impacts (such as carbon footprint, water footprint, solid waste, liquid waste, recycled material use), social sustainability of its supply chain to survive in global competition. The management observed that the environmental footprint of the supply chain significantly depends on raw material footprint, ordering policy, and transportation associated with the product. The company faces a dilemma, how much to source from a particular supplier to make a balance between three sustainability dimensions. The model considers a few assumptions, which are discussed below.

The range of the demand for each period is known, and it is shared with the suppliers.

Each period in this model is considered a month. 
$\square$ The model does not consider the backorder or shortage, variation of lead time, late delivered item, and price breaks.

$\square \quad$ All the products are available to all the suppliers.

One type of container is considered for this model.

$\square$ Discarded products are disposed of at the scrap value during the same period and not further considered for the inventory that is carried across a period within the planning horizon.

$\square \quad$ Inventory holding cost is considered for the model when the product is carried across a period in the planning horizon.

$\square \quad$ The suppliers have a finite capacity to supply. Each period ordering cost for a particular supplier is fixed, and it does not vary with the number of products.

Our proposed model has three objectives (cost, emission, and social sustainability), which are conflicting in nature. The manufacturer is interested in estimating the lot-size, which can reduce the total cost, emission and maximize the social score of the sourcing.

To develop the model following indices, parameters, and variables are considered. Variables having a tilde $(\sim)$ over them represents the uncertainty. The uncertainty has been quantified through the triangular fuzzy number.

Indices

$s$ - Index of the suppliers, $s \in 1,2, \ldots, S$

$m$ - Index of the products, $m \in 1,2, \ldots, M$

$t$ - Index of the time periods, $t \in 1,2, \ldots, T$

Parameters

$\widetilde{O_{s t}}$ Ordering cost for order placed to the supplier $s$ at the time period $t$

$\widetilde{P_{s m}}$ Cost of the productm purchased from supplier $s$ at time period $t$

$\operatorname{tax}_{s}$ Tax percentage at supplier $s$

$\widetilde{H C_{s t}}$ Handling cost of the lot coming from supplier $s$ at time period $t$

$\widetilde{T C_{s t}}$ Transportation cost of lot coming from supplier $s$ to manufacturer at time period $t$

$\widetilde{H_{m}}$ Holding cost of product $m$ at time period $t$

$\widetilde{E C F_{s m}}$ Embodied carbon footprint of product $m$ purchased from supplier $s$

$\widetilde{T E_{s t}}$ Transportation emission of lot procured from supplier $s$ at time period $t$

$\widetilde{H E_{m t}}$ Holding emission of product $m$ at time period $t$ 
$\widetilde{W F_{s m}}$ Water footprint of the product $m$ purchased from the supplier $s$

$W F^{c a p}$ Water footprint cap of the procured material

$\widetilde{S W_{s m}}$ Solid waste generated during manufacturing product $m$ at supplier $s$

$S W^{c a p}$ Solid waste cap over the procured material

$\widetilde{L W_{s m}}$ Liquid waste generated during manufacturing product $m$ at supplier $s$

$L W^{c a p}$ Liquid waste cap over the procured material

$\widetilde{R M_{s m}}$ Recycled material used for manufacturing product $m$ purchased from supplier $s$

$R M$ Minimum recycled amount used of the procured materials

$\widetilde{Q R_{s m}}$ Quality rejection percentage of product $m$ purchased from supplier $s$

$D_{m t}$ Demand of product $m$ at time period $t$

$\widetilde{J_{s t}}$ Supplying capacity of supplier $s$ at time period $t$

$M F_{t}$ Storage capacity of the manufacturer at time period $t$

$\widetilde{C C_{s t}}$ Container capacity coming from supplier $s$ at time period $t$

$M O_{s t}$ Minimum order size from supplier $s$ at time period $t$

$\widetilde{S S_{S}}$ Social score of the supplier $s$

Decision variables

$X_{s m t}$ Lot-size of the product $m$ purchased from supplier $s$ at time period $t$

$I_{m t}$ Inventory of the product $m$ at time period $t$

$Z_{s t} \in\{0,1\} 1$ if an order is placed to supplier $s$ at time period $t$ else 0

\subsection{Model}

The proposed model deals with multiple objectives. The multi-objective model can portray the real-life situation efficiently as compared to a single objective model. The first objective of the model is to minimize the total sourcing cost. The objective consists of six parts: ordering cost, purchasing cost, transportation cost, inventory holding cost, purchasing tax, and handling cost. In this study, all the costs are considered as fuzzy in nature, which follows the triangular membership function. The fuzzy variables are denoted by $(\sim)$. It is assumed that for every order, a specific amount of cost is incurred. The ordering cost, shown in Eqn. (1a), depends on the value of the binary variable $\left(Z_{s t}\right)$. The total purchasing cost, shown in Eqn. (1b), can be calculated by multiplying unit possibilistic product cost and the volume purchased from the suppliers. The transportation cost, shown in Eqn. (1c), depends on the possibilistic transportation cost of the container 
and the binary value $\left(Z_{s t}\right)$. The inventory holding cost, depicted in Eqn. (1d), depends on the amount of inventory held in the system and the corresponding carrying cost of that inventory. Eqn. (1e) calculates the total purchasing tax of the lot. The tax has been calculated based on the total purchase price of the product. Eqn. (1f) determines the handling cost of the procurement.

$$
\begin{aligned}
& \text { Minimize TC }=\text { ordering cost }+ \text { purchasing cost }+ \text { transportation cost }+ \\
& \text { Inventory holding cost }+ \text { purchasing tax }+ \text { handling cost } \\
& \text { Ordering cost }=\sum_{s=1}^{S} \sum_{t=1}^{T} \widetilde{O_{s t}} Z_{s t} \\
& \text { Purchasing cost }=\sum_{S=1}^{S} \sum_{m=1}^{M} \sum_{t=1}^{T} \widetilde{P_{s m}} X_{s m t} \\
& \text { Transportation cost }=\sum_{s=1}^{S} \sum_{t=1}^{T} \widetilde{T C_{s t}} Z_{s t} \\
& \text { Inventory holding cost }=\sum_{m=1}^{M} \sum_{t=1}^{T} \widetilde{H_{m t}} I_{m t} \\
& \text { Purchasing tax }=\sum_{S=1}^{S} \sum_{m=1}^{M} \sum_{t=1}^{T} \widetilde{P_{s m}} \operatorname{tax}_{s} X_{\text {smt }} \\
& \text { Handling cost }=\sum_{s=1}^{S} \sum_{t=1}^{T} \widetilde{H C_{s t}} Z_{s t}
\end{aligned}
$$

With increasing concern about carbon footprint reduction of the business processes, this study attempts to quantify the carbon footprint of the sourcing. Carbon footprint quantification has multiple benefits nowadays. It helps the manufacturers to mitigate the emission-related risks that emerge from the governments and NGOs. The second objective attempts to minimize the emissions of the procurement. Eqn. (2a) and (2b) calculate the embodied carbon footprint of the raw material and transportation, respectively. The current study does not focus on the micro-level of quantification of the carbon footprint. This embodied carbon footprint can be measured by a popularly available standard like PAS 2050 (2011) developed by British Standard Institution. The total embodied carbon footprint can be calculated by multiplying the individual carbon footprint of the supplied product with the lot-size. Similarly, transportation emission is calculated by multiplying the binary variable with the emission to transport the container. Transportation emission is applicable when an order is placed to the supplier at a particular time period. Eqn. (2c) estimates the emission pertaining to the inventory holding at the manufacturing unit. The 
holding emission is significant for the perishable products, where a significant amount of carbon is emitted for holding the inventory.

Minimize TE = Embodied carbon footprint of product + Transportation carbon emission

+ Emission for holding the inventory

Embodied carbon footprint $=\sum_{S=1}^{S} \sum_{m=1}^{M} \sum_{t=1}^{T} \widetilde{E C F_{s m}} X_{s m t}$

Transportation carbon emission $=\sum_{S=1}^{S} \sum_{t=1}^{T} \widetilde{T E_{s t}} Z_{s t}$

Holding emission of the product $=\sum_{m=1}^{M} \sum_{t=1}^{T} \widetilde{H E_{m t}} I_{m t}$

Maximize TSS $=\sum_{S=1}^{S} \sum_{m=1}^{M} \sum_{t=1}^{T} \widetilde{\tilde{S} S} X_{s m t}$

The third objective of this model is to maximize the social score of the procurement. Social sustainability has gained noteworthy attention nowadays due to increasing concern about fair working practices. Nowadays, the manufacturing firm cannot ignore the societal condition of its suppliers for the sake of cost reduction. Hence, it should be safe for the manufacturer if they consider the social issues in the material procurement to avoid the outrage of the governments and NGOs. Eqn. (3) calculates the total social score of the procurement. The social score estimated by BWM and TOPSIS method has been used in the model. Constraints

Constraints in Eqn. (4) represent the inventory balance of the model. In this study, we have assumed quality and demand as fuzzy variables. In literature, a significant few lot-sizing models were reported considering the fuzzy quality. The fuzzy variables help to mitigate the risks more efficiently as compared to the deterministic model.

$$
\begin{aligned}
& I_{m t}=\sum_{s=1}^{S} X_{s m t}-\sum_{s=1}^{S} \widetilde{Q R_{s m}} X_{s m t}-D_{m t} \quad \forall m, t=1 \\
& I_{m t}=I_{m(t-1)}+\sum_{s=1}^{S} X_{s m t}-\sum_{s=1}^{S} \widetilde{Q R_{s m}} X_{s m t}-D_{m t} \quad \forall m, t=2 . . T
\end{aligned}
$$

Constraints in Eqn. (5) ensure that the buyer cannot place an order without expensing the ordering cost. The binary variable decides in which period order is to be placed to a particular supplier. 


$$
X_{s m t} \leq\left(\sum_{t=1}^{T} D_{m t}\right) Z_{s t} \quad \forall s, m, t
$$

Constraints in Eqn. (6) manage the capacity of the suppliers. The capacities of the suppliers are considered as uncertain variables. The constraint ensures that the lot size amount should not go beyond the uncertain capacity of the supplier.

$$
\sum_{m=1}^{M} X_{s m t} \leq \widetilde{J_{s t}} \forall s, t
$$

Constraint (7) deals with the inventory holding capacity of the manufacturer. This constraint ensures that the inventory holding amount for a particular period should not go beyond the holding capacity of the manufacturer.

$$
\sum_{m=1}^{M} I_{m t} \leq M F_{t} \quad \forall t
$$

Constraint (8) ensures that the lot-size amount should not go beyond the capacity of the container.

$$
\sum_{m=1}^{M} X_{s m t} \leq \widetilde{C C_{s t}} \quad \forall s, t
$$

Constraint (9) ensures the minimum ordering constraint from the supplier. The manufacture places the order to the supplier if it crosses a certain amount. The minimum ordering constraint is employed to obtain the facilities of order batching.

$$
\sum_{m=1}^{M} X_{s m t} \geq M O_{s t} Z_{s t} \quad \forall s, t
$$

The constraint in Eqn. (10) handles the water footprint of the material for procurement. The water footprint is a relatively neglected issue for making procurement decisions. As of now, most of the archived studies have considered the carbon footprint to deal with environmental issues. However, this study argues that water footprint is equally a pressing issue due to diminishing freshwater at a faster rate for industrial use. To rectify the problem, the water footprint needs to be incorporated into the procurement stage. In this study, the water footprints of the raw materials are considered as uncertain variables. The water footprint of the material should not go beyond the estimated water cap. The water footprint constraint is taken in the direction of Kantas et al. (2015) and Heck and Schmidt (2010). 
$\sum_{s=1}^{S} \sum_{m=1}^{M} \sum_{t=1}^{T} \widetilde{W F_{s m}} X_{s m t} \leq W F^{c a p}$

Constraint in Eqn. (11) estimates the recycled material used for manufacturing the raw material. To implement sustainability, it is imperative to use recycled material in the manufacturing process. A significant amount of studies have reported the recycled material usage for green supply chain network design. However, recycled material consideration in the context of lot sizing is uncommon. Similar to carbon and water footprint, the recycled material use for manufacturing the product is also considered as fuzzy. The constraint ensures a minimum amount of recycled material use in the manufacturing of the material. The constraint has been implemented, taking insights from Govindan and Sivakumar (2016).

$$
\sum_{S=1}^{S} \sum_{m=1}^{M} \sum_{t=1}^{T} \widetilde{R M_{s m}} X_{s m t} \geq R M
$$

Constraint in Eqn. (12) determines the total solid waste for purchasing the material. For implementing sustainability, it is essential to quantify the solid waste at the supplier level. The constraint is implemented, taking insights from Humphreys et al. (2003).

$$
\sum_{s=1}^{S} \sum_{m=1}^{M} \sum_{t=1}^{T} \widetilde{S W_{s m}} X_{s m t} \leq S W^{c a p}
$$

Constraint in Eqn. (13) quantifies the total liquid waste for purchasing the material. The constraint is taken, taking insights from Humphreys et al. (2006).

$$
\sum_{s=1}^{S} \sum_{m=1}^{M} \sum_{t=1}^{T} \widetilde{L W_{s m}} X_{s m t} \leq L W^{c a p}
$$

Constraint in Eqn. (14) ensures the non-negativity of the variables. All the decision variables should be greater than or equal to zero.

$$
X_{s m t} \geq 0 \quad \forall s, m, t
$$

Constraint in Eqn. (15) portrays the binary nature of the variable.

$$
Z_{s t} \in\{0,1\} \quad \forall s, t
$$

\subsection{Research methodology}

The current study proposed a three-stage method to handle the proposed sustainable lot-sizing problem. In the first stage, the social scores of the suppliers are calculated by using the Best Worst Method (BWM) and TOPSIS. In the second stage, the scores are used in the multi-objective possibilistic lot-sizing model. In the 
third stage, the e-constraint method is used to generate a trade-off relationship among the conflicting objectives. The description of BWM, TOPSIS, possibilistic programming, and $\varepsilon$-constraint method are given below.

\subsubsection{Description of $B W M$}

Best-Worst Method (BWM) was proposed by Rezaei (2015). The BWM works on the principle of pairwise comparison by using a scale of 1 to 9 . More specifically, the computation of this method is based on two vectors called best and worst. A decision-maker has to perform pairwise comparisons bases on Best and Worst factors. The BWM has several benefits over AHP, which is a very popular technique in management studies. AHP method requires $n(n-1) / 2$ pairwise comparisons, while BWM needs only (2n-3) pairwise comparisons. BWM requires fewer data and provides higher consistency. The technique has received significant attention from researchers and has been utilized standalone or combined with different approaches to solve management problems (You et al. 2017; Cheraghalipour et al. 2018). The working principles of BWM are shown below.

\section{Steps associated with BWM}

1. Suppose an MCDM problem consists of a set of ' $n$ ' criteria, i.e., $\left\{c_{1}, c_{2}, \ldots c_{n}\right\}$.

2. Among the identified criteria, a decision-maker has to choose the most desirable or best criteria $\left(C_{B}\right)$ and the least important or worst criteria $\left(C_{W}\right)$, respectively.

3. After identifying the Best and worst criterion, the decision-maker has to estimate the best social criteria preference over all other social criteria using a $1-9$ scale. In the pairwise comparison, 1 illustrates equal importance between the best to other criteria, and 9 expresses the extreme importance of the best criteria over the other criteria. The Best-to-other (BO) vector can be expressed as $A_{B}=\left(\alpha_{B 1}, \alpha_{B 2}, \ldots \alpha_{B n}\right)$, where $\left(\alpha_{B n}\right)$ marks the preference of Best criterion (B) to other criteria 'j' and $\left(\alpha_{B B}=1\right)$.

4. Similarly, using a scale of 1-9, the preference of others to the worst factor is performed. The vector "other to worst" can be expressed as $A_{W}=\left(\alpha_{1 W}, \alpha_{2 W}, \ldots \alpha_{n W}\right)^{T}$, where $\left(\alpha_{j W}\right)$ depicts the preference of criterion 'j' over worst criterion $(\mathrm{W})$ and $\left(\alpha_{W W}=1\right)$.

5. Subsequently, optimal weights of factors can be calculated $\left(W_{1}^{*}, W_{2}^{*}, W_{3}^{*}, \ldots W_{n}^{*}\right)$. Optimal weights are obtained by solving the Minmax model suggested by (Rezaei 2016).

$$
\min \max (j)=\left\{\left|\frac{W_{B}}{W_{j}}-\alpha_{B j}\right|,\left|\frac{W_{j}}{W_{W}}-\alpha_{j W}\right|\right\}
$$


$W_{j} \geq 0, \quad \forall$ all $j$

The min-max model can be transformed into an equivalent linear programming problem:

$$
\begin{aligned}
& \min \varphi^{1} \\
& \left|W_{B}-\alpha_{B j} w_{j}\right| \leq \varphi^{1}, \quad \forall \text { all } j \\
& \left|W_{j}-\alpha_{j w} W_{W}\right| \leq \varphi^{1}, \quad \forall \text { all } j \\
& \sum_{j} W_{j}=1 \\
& W_{j} \geq 0, \quad \forall \text { all } j
\end{aligned}
$$

According to Rezaei (2016) if the value of $\varphi^{1}$ falls nearer to zero, then the model can be considered consistent.

\subsubsection{Description of TOPSIS}

After obtaining the weights of factors from BWM, the ranking of the alternatives is accomplished through the TOPSIS method. The steps of TOPSIS are discussed below. TOPSIS is a well know MCDM method, which was developed by Hwang and Yoon (1981). Due to the ease of use and reliability, this method has been applied to solve various ranking problems (Gupta and Barua, 2018). TOPSIS method is based on the principle of geometric distance. The final scores of alternatives are defined on the basis of Euclidean distance. The worst score is nearest to the negative ideal solution, and the best score is close to the positive ideal solution (You et al. 2017).

\section{Steps associated with TOPSIS}

6. For estimating the alternatives' ranking, a decision matrix ' $K$ ' is formed, as shown below in equation (3).

$$
K=\begin{array}{c|ccc}
A_{1} & c_{1} & c_{2} & c_{m} \\
\vdots & f_{11} & \cdots & f_{1 n} \\
A_{n} & \vdots & \vdots & \vdots \\
f_{m 1} & f_{m 2} & f_{m n}
\end{array} \mid
$$

Where, $A_{n}$ denotes the potential alternatives $(n=1,2, \ldots \ldots N) ; C_{m}$ Represents the factors used for rating the alternatives. $f_{m n}$ is a crisp value showing the rating of individual alternatives with respect to each factor $C_{m}$ 
7. The rating shown in the matrix $\mathrm{K}$ is normalized by using Eqn. 4. In this equation $A_{m n}$ can be calculated as follows.

$$
A_{m n}=\frac{f_{m n}}{\sqrt{\sum_{n=1} f_{m n}^{2}}} m=1,2, \ldots \ldots M, n=1,2, \ldots \ldots N
$$

8. Further, the weighted normalized decision matrix $\left(L_{m n}\right)$ is estimated through $L_{m n}=W_{m} \times f_{m n}$, where $W_{m}$ denotes the weights of the $m^{t \square}$ criteria calculated by BWM method.

9. After obtaining the weighted matrix, the positive ideal $\left(p^{+}\right)$and negative ideal solutions $\left(p^{-}\right)$are calculated. In the below formulation $\left(n^{\prime}\right)$ denotes the factors pertaining to benefits.

$$
\begin{aligned}
& p^{+}=\left(L_{1}, L_{2}, \cdots \cdots L_{m}\right)=\left(\max _{n} L_{m n}\right) n \in n^{\prime} \\
& p^{-}=\left(L_{1}, L_{2}, \cdots \cdots L_{m}\right)=\left(\min _{n} L_{m n}\right) n \in n^{\prime}
\end{aligned}
$$

10. Compute the Euclidean distance from the positive ideal and negative ideal solutions using equations 6 and 7.

$$
\begin{aligned}
& K_{n}^{+}=\sqrt{\sum_{m=1}^{M}\left(L_{m n}-p_{m}^{+}\right)^{2}} \\
& K_{n}^{-}=\sqrt{\sum_{m=1}^{M}\left(T_{m n}-p_{m}^{-}\right)^{2}}
\end{aligned}
$$

11. Lastly, the performance score is calculated using equation 8 .

$$
S S_{n}=\frac{K_{n}^{-}}{K_{n}^{+}+K_{n}^{-}}
$$

$S S_{n}$ value signifies the coefficient of alternatives, which lies between 0 to 1 . The alternative with the highest $S S_{n}$ is termed as the best alternatives.

\subsubsection{Possibilistic programming}

Uncertainty is a common phenomenon of any real-life business problem. An uncertain model can handle real-life situations more effectively as compared to the deterministic model. Dubois et al. (2003) classified the uncertainties into two categories, such as (a) uncertainty in data and (b) flexibility in constraints and goals. Flexibility can be represented by tolerance to goals and constraints values, which can be handled by using the flexible mathematical programming model (Bellman and Zadeh, 1970; Mula et al. 2006; Pishvaee

and Razmi, 2011). The uncertainty in data is broadly classified into two segments, such as (a) randomness and (b) Epistemic uncertainty (Pishvaee and Torabi, 2010; Pishvaee and Razmi, 2011). Randomness, which 
often comes from random variables, can be handled by using stochastic programming. On the other hand, possibilistic programming is generally applied to deal with Epistemic uncertainty (PishvaeeandRazmi, 2011). Stochastic programming is applied to situations where the decision-makers have a clear idea about the distribution of the data. On the other hand, possibilistic programming can be applied without knowing the distribution.

In this paper, we are applying possibilistic programming to handle the uncertainty of the parameters. In possibilistic programming, each ill-known parameter has its own possibilistic distribution. Pishvaee and Torabi (2010), Pishvaee and Razmi (2011), and Inuiguchi and Ramik (2000) efficiently discussed how to define possibilistic variables. Possibilistic distribution is dependent on the judgment of decision-makers. To solve the lot-sizing model, two-stage methods are adopted. Firstly, we apply the Jimenez et al. (2007) principle to convert the multi-objective possibilistic model into an equivalent auxiliary crisp model. In the second phase, we have applied the $\varepsilon$-constrained method to obtain compromise solutions between the objectives.

The present study considers $(\widetilde{€})$ as a fuzzy parameter, which can be represented by a triangular fuzzy number. In a fuzzy number, let us assume $€^{A}, €^{B}$ and $€^{C}$ as left displacement, center value, right displacement, respectively. By using the triplet, the fuzzy membership function $(\tilde{\phi})$ can be denoted as follows:

$$
\mu_{\widetilde{\phi}}(x)= \begin{cases}f_{\phi}(x)=\frac{x-\phi^{A}}{\phi^{B}-\phi^{A}} & \text { if } \phi^{A} \leq x \leq \phi^{B} \\ 1 & \text { if } x=\phi^{B} \\ g_{\phi}(x)=\frac{\phi^{c}-x}{\phi^{c}-\phi^{B}} & \text { if } \phi^{B} \leq x \leq \phi^{c} \\ 0 & \text { if } x \leq \phi^{A} \text { or } x \geq \phi^{c}\end{cases}
$$

The current study has adopted the method of Jiménez et al. (2007) to calculate the expected interval (EI) and expected value $(\mathrm{EV})$ of $\operatorname{TFN}(\widetilde{€})$.

$$
\begin{aligned}
& E I(\tilde{\phi})=\left[E_{1}^{\phi}, E_{2}^{\phi}\right]=\left[\frac{1}{2}\left(\phi^{A}+\phi^{B}\right), \frac{1}{2}\left(\phi^{B}+\phi^{C}\right)\right] \\
& E V(\tilde{\phi})=\frac{E_{1}^{\phi}+E_{2}^{\phi}}{2}=\frac{\phi^{A}+2 \phi^{B}+\phi^{C}}{4}
\end{aligned}
$$

Jiménez et al. (2007) suggested that for any pair of fuzzy numbers $\tilde{a}$ and $\tilde{b}$, the degree in which $\tilde{a}$ is greater than $\tilde{b}$ can be denoted as. 


$$
\mu_{\tilde{m}}(\tilde{a}, \tilde{b})= \begin{cases}0 & \text { if } E_{2}^{a}-E_{1}^{b}<0 \\ \frac{E_{2}^{a}-E_{1}^{b}}{\left(E_{2}^{a}-E_{1}^{b}\right)-\left(E_{1}^{a}-E_{2}^{b}\right)} & \text { if } 0 \in\left[E_{1}^{a}-E_{2}^{b}, E_{2}^{a}-E_{1}^{b}\right] \\ 1 & \text { if } E_{1}^{a}-E_{2}^{b}<0\end{cases}
$$

When $\mu_{\widetilde{M}}(\tilde{a}, \tilde{b}) \geq \alpha$ it will be represented as $\tilde{a} \geq_{\alpha} \tilde{b}$. Now, let us assume a fuzzy linear programming model in which all parameters are defined as TFN.

In this direction, Parra et al. (2005) suggested an important definition of fuzzy numbers. For any pair of fuzzy numbers $(\tilde{a})$ and $(\tilde{b})$, it can be established that $\tilde{a}$ is indifferent to $\tilde{b}$ in the degree of $\alpha$ if the following relationships hold true.

$$
\tilde{a} \geq_{\frac{\alpha}{2}} \tilde{b}, \tilde{a} \leq_{\frac{\alpha}{2}} \tilde{b}
$$

The above equation can be represented as follows:

$$
\frac{\alpha}{2} \leq \mu_{M}(\tilde{a}, \tilde{b}) \leq 1-\frac{\alpha}{2}
$$

Fuzzy mathematical programming can be denoted as follows.

$$
\min z=\tilde{\phi}^{k} x
$$

s.t.

$\tilde{a}_{i} x \geq \tilde{b}_{i}, i=1, \ldots \ldots, l$

$\tilde{a}_{i} x=\tilde{b}_{i}, i=l+1, \ldots \ldots, m$

$x \geq 0$

By applying the concept of EV and EI by Jiménez et al. (2007) and the theory of Parra et al. (2005), the equivalent crisp $\alpha$-parametric model of the aforementioned fuzzy linear programming can be transformed as follows:

$$
\min =E V(\tilde{\phi}) x
$$

s.t.

$$
\begin{aligned}
& {\left[(1-\alpha) E_{2}^{a i}+\alpha E_{1}^{a i}\right] x \geq \alpha E_{2}^{b i}+(1-\alpha) E_{1}^{b i}, i=1, \ldots \ldots, l} \\
& {\left[\left(1-\frac{\alpha}{2}\right) E_{2}^{a i}+\frac{\alpha}{2} E_{1}^{a i}\right] x \geq \frac{\alpha}{2} E_{2}^{b i}+\left(1-\frac{\alpha}{2}\right) E_{1}^{b i}, i=l+1, \ldots \ldots, m} \\
& {\left[\frac{\alpha}{2} E_{2}^{a i}+\left(1-\frac{\alpha}{2}\right) E_{1}^{a i}\right] x \leq\left(1-\frac{\alpha}{2}\right) E_{2}^{b i}+\frac{\alpha}{2} E_{1}^{b i}, i=l+1, \ldots \ldots, m} \\
& x \geq 0
\end{aligned}
$$




\subsubsection{E-constraint method}

Various methods have been suggested in the literature to handle the multi-objective problem. Among them, fuzzy programming methods have been extensively used in the literature for its ability to satisfy the objective functions explicitly. Zimmermann (1978) proposed the concept of fuzzy programming, which further enriched by the study of various authors (Tanaka and Asai, 1984; Tiwari et al. 1987; Sakawa et al. 1987; Delgado et al. 1989; Lai and Hwang, 1993; Guu and Wu, 1999). Recently, Selim and Ozkarahan (2008), Torabi and Hassini (2008), and Li et al. (2006) proposed some advanced methods to handle fuzzy programming. We have adopted the $\varepsilon$-constraint method proposed by Pishvaee and Razmi (2012) for the lot-sizing model. $\varepsilon$-constraint method can generate various Pareto optimal solutions that give a clear picture of the Pareto optimal set. This tool helps the manager to make the decision more confidently based on available information. For more information about $\varepsilon$-constraint method, readers are referred to Hwang and Masud (1979), Ehrgott (2005), and Engau and Wiecek (2007). The $\varepsilon$-constraint method is a popular technique to handle conflicting management goals. The method often converts a multi-objective problem into an equivalent single objective model by placing the other objectives in the constraint (Tosarkani and Amin, 2018).

Let us assume a multi-objective crisp problem as follows:

$$
\begin{aligned}
& \max \left(\lambda_{1}(x), \lambda_{2}(x), \ldots \ldots \lambda_{n}(x)\right) \\
& \text { s.t. } \\
& x \in U,
\end{aligned}
$$

Where (x) represents the decision vector, $\lambda_{n}(x)$ denotes the membership functions of the (n) objectives, and (U) signifies the feasible region. The multi-objective fuzzy model can be converted into the $\varepsilon$-constraint model.

$$
\begin{aligned}
& \max \lambda_{1}(x) \\
& \text { s.t. } \\
& \lambda_{2}(x) \geq \varepsilon_{2} \\
& \ldots \\
& \lambda_{n}(x) \geq \varepsilon_{n}, \\
& x \in U, \\
& \varepsilon \in[0,1] .
\end{aligned}
$$




\section{Proposed hybrid solution approach:}

The current study proposes a three-stage approach to handle the lot-sizing problem. The details of the proposed solution methodology are given below.

\section{Stage 1: Quantification of the social score of the suppliers}

Initially, social sustainability factors are to be identified.

$\square$ Develop a hierarchical decision-making structure using identified factors.

$\square$ Apply the BWM method to get the weights of the factors

$\square$ Apply the TOPSIS to estimate the score of the alternatives.

\section{Stage 2: Development of the possibilistic lot-sizing model}

The alternatives scores estimated in stage 1 are used in stage 2 for developing the multi-objective possibilistic lot-sizing model. The fuzzy model is to be converted into the equivalent deterministic model using the earlier discussed theories. The steps of stage 2 are given below.

1. The lot-sizing model is converted to an equivalent auxiliary crisp model by applying the Jimenez et al. (2007) and Parra et al. (2005) principles. The objective functions of the lot-sizing model are converted to crisp ones using the expected value of imprecise parameters. Then, the $\alpha$ value is decided to convert the fuzzy constraints into the equivalent crisp constraints.

2. After transformation to the crisp formulation, the membership functions of the multi-objective problems can be calculated by solving the objectives separately. The membership functions are calculated in the line of Amid et al. (2006) and Zimmerman et al. (1978).

3. The membership function of the objective functions can be computed as follows.

If the objective function is minimizing in nature, the membership function can be calculated as:

$$
\mu_{1}(x)= \begin{cases}1 & \text { if } W_{1} \leq W_{1}^{\alpha \min } \\ \frac{W_{1}^{\alpha \max }-W_{1}}{W_{1}^{\alpha \max }-W_{1}^{\alpha \min }} & \text { if } W_{1}^{\alpha \min } \leq W_{1} \leq W_{1}^{\alpha \max } \\ 0 & \text { if } W_{1} \geq W_{1}^{\alpha \max }\end{cases}
$$

Where $W_{1}$ is the objective function and $W_{1}^{\alpha \max }=\max W_{1}$ and $W_{1}^{\alpha \min }=\min W_{1}$

If the objective function is maximizing in nature, the membership function can be calculated as:

$$
\mu_{2}(x)= \begin{cases}1 & \text { if } W_{2} \geq W_{2}^{\alpha \max } \\ \frac{W_{2}-W_{2}^{\alpha \min }}{W_{2}^{\alpha \max }-W_{2}^{\alpha \min }} & \text { if } W_{2}^{\alpha \min } \leq W_{2} \leq W_{2}^{\alpha \max } \\ 0 & \text { if } W_{2} \leq W_{2}^{\alpha \min }\end{cases}
$$

Where $W_{1}$ is the objective function and $W_{2}^{\alpha \max }=\max W_{2}$ and $W_{2}^{\alpha \min }=\min W_{2}$

The membership function $\mu_{\square}(x)$ represents the degree of satisfaction of a fuzzy goal. 


\section{Stage 3: Solving the model and generating the solution}

1. The multi-objective crisp lot-sizing model can be transformed into a single objective model by using $\varepsilon$ -constraint method. In this case, the satisfaction degree of the objective function is maximized by putting the remaining objectives' aspirations in the constraint. The aspiration value of the objective function can be controlled by $\varepsilon$-value.

2. The value $\varepsilon$ is varied to obtain the different Pareto optimal solutions over the whole efficient set. In this method, the values of $(\varepsilon)$ lie between 0 and 1 . For infeasibility, the value of $(\varepsilon)$ can be adjusted as per the requirements of decision-makers.

3. If the decision-maker is satisfied with the solution, then stop that point and select the solution. Otherwise, the value $\varepsilon$ can be varied to get the preferred solution.

4. If the decision-maker wants to change the value of $\alpha$; for that case, the calculation is to be restarted from step 1 .

\section{The equivalent auxiliary crisp model}

Various studies have proposed different methods to deal with possibilistic programming (Lai and Hwang, 1992; Parra et al. 2005; Jimenez et al. 2007; Liang, 2006; Kabak and Ülengin, 2011). Among these methods, we have adopted Jimenez et al. (2007) principle for its ability to handle triangular and trapezoidal functions without increasing the complexity of the problem. This method preserves the number of objectives and constraints the same, which helps to solve the model quickly than other methods. For more information, readers may refer to Jimenez et al. (2007), Pishvaee and Razmi (2012), and Parra et al. (2005). Applying the principles of Jimenez et al. (2007) and Parra et al. (2005), and Pishvaee and Razmi (2012), the lot-sizing problem (Equation 1-9) can be transformed as follows:

$$
\begin{aligned}
& \operatorname{Min} T C=\sum_{s=1}^{S} \sum_{t=1}^{T}\left(\frac{O_{s t}^{p e s}+2 O_{s t}^{m o s}+O_{s t}^{o p t}}{4}\right) Z_{s t}+\sum_{s=1}^{S} \sum_{m=1}^{M} \sum_{t=1}^{T}\left(\frac{P_{s m}^{p e s}+2 P_{s m}^{m o s}+P_{s m}^{o p t}}{4}\right) X_{s m t}+ \\
& \sum_{s=1}^{S} \sum_{t=1}^{T}\left(\frac{T C_{s t}^{p e s}+2 T C_{s t}^{m o s}+T C_{s t}^{o p t}}{4}\right) Z_{s t}+\sum_{m=1}^{M} \sum_{t=1}^{T}\left(\frac{H_{m t}^{p e s}+2 H_{m t}^{m o s}+H_{m t}^{o p t}}{4}\right) I_{m t}+ \\
& \sum_{s=1}^{S} \sum_{m=1}^{M} \sum_{t=1}^{T}\left(\frac{P_{s m}^{p e s}+2 P_{s m}^{m o s}+P_{s m}^{o p t}}{4}\right) \operatorname{tax}_{s} X_{s m t}+\sum_{s=1}^{S} \sum_{t=1}^{T}\left(\frac{H C_{s t}^{p e s}+2 H C_{s t}^{m o s}+H C_{s t}^{o p t}}{4}\right) Z_{s t}
\end{aligned}
$$




$$
\begin{array}{r}
\operatorname{Min} T E=\sum_{s=1}^{S} \sum_{m=1}^{M} \sum_{t=1}^{T}\left(\frac{E C F_{s m}^{p e s}+2 E C F_{s m}^{m o s}+E C F_{s m}^{o p t}}{4}\right) X_{s m t} \\
+\sum_{s=1}^{S} \sum_{t=1}^{T}\left(\frac{T E_{s t}^{p e s}+2 T E_{s t}^{m o s}+T E_{s t}^{o p t}}{4}\right) Z_{s t}+ \\
\sum_{m=1}^{M} \sum_{t=1}^{T}\left(\frac{H E_{m t}^{p e s}+2 H E_{m t}^{m o s}+H E_{m t}^{o p t}}{4}\right) I_{m t} \\
\operatorname{Max} T S S=\sum_{s=1}^{S} \sum_{m=1}^{M} \sum_{t=1}^{T}\left(\frac{S S_{s}^{\text {pes }}+2 S S_{s}^{m o s}+S S_{s}^{o p t}}{4}\right) X_{s m t}
\end{array}
$$

Subject to,

$$
\begin{aligned}
& I_{m t}-\sum_{s=1}^{S} X_{s m t}+\sum_{s=1}^{S}\left\{\left(\frac{\alpha}{2}\right)\left(\frac{Q R_{s m}^{o p t}+Q R_{s m}^{m o s}}{2}\right)+\left(1-\frac{\alpha}{2}\right)\left(\frac{Q R_{s m}^{p e s}+Q R_{s m}^{m o s}}{2}\right)\right\} X_{s m t}+D_{m t} \leq 0 \\
& I_{m t}-\sum_{s=1}^{S} X_{s m t}+\sum_{s=1}^{S}\left\{\left(1-\frac{\alpha}{2}\right)\left(\frac{Q R_{s m}^{o p t}+Q R_{s m}^{m o s}}{2}\right)+\left(\frac{\alpha}{2}\right)\left(\frac{Q R_{s m}^{p e s}+Q R_{s m}^{m o s}}{2}\right)\right\} X_{s m t}+D_{m t} \geq 0
\end{aligned}
$$

$\forall m, t=1$

$$
\begin{aligned}
I_{m t}-I_{m(t-1)}- & \sum_{s=1}^{S} X_{s m t}+\sum_{s=1}^{S}\left\{\left(\frac{\alpha}{2}\right)\left(\frac{Q R_{s m}^{o p t}+Q R_{s m}^{m o s}}{2}\right)+\left(1-\frac{\alpha}{2}\right)\left(\frac{Q R_{s m}^{\text {pes }}+Q R_{s m}^{\text {mos }}}{2}\right)\right\} X_{s m t} \\
& +D_{m t} \leq 0 \\
I_{m t}-I_{m(t-1)}- & \sum_{s=1}^{s} X_{s m t}+\sum_{s=1}^{S}\left\{\left(1-\frac{\alpha}{2}\right)\left(\frac{Q R_{s m}^{o p t}+Q R_{s m}^{\text {mos }}}{2}\right)+\left(\frac{\alpha}{2}\right)\left(\frac{Q R_{s m}^{\text {pes }}+Q R_{s m}^{m o s}}{2}\right)\right\} X_{s m t} \\
& +D_{m t} \geq 0
\end{aligned}
$$

$\forall m, t=2 . . T$

$$
\begin{aligned}
& X_{s m t} \leq\left[\sum_{t=1}^{T} D_{m t}\right] Z_{s t} \forall s, m, t \\
& X_{s m t} \leq\left[\alpha\left(\frac{J_{s m t}^{p e s}+J_{s m t}^{m o s}}{2}\right)+(1-\alpha)\left(\frac{J_{s m t}^{m o s}+J_{s m t}^{o p t}}{2}\right)\right] \quad \forall s, m, t
\end{aligned}
$$

$\sum_{m=1}^{M} I_{m t} \leq W_{m t} \quad \forall t$

$\sum_{m=1}^{M} X_{s m t} \leq\left[\alpha\left(\frac{C C_{s t}^{p e s}+C C_{s t}^{m o s}}{2}\right)+(1-\alpha)\left(\frac{C C_{s t}^{m o s}+C C_{s t}^{o p t}}{2}\right)\right] \forall s, t$ 


$$
\begin{aligned}
& \sum_{m=1}^{M} X_{s m t} \leq M O_{s t} Z_{s t} \forall s, t \\
& W F^{c a p} \geq \sum_{s=1}^{S} \sum_{m=1}^{M} \sum_{t=1}^{T}\left\{\alpha\left(\frac{W F_{s m}^{o p t}+W F_{s m}^{m o s}}{2}\right)+(1-\alpha)\left(\frac{W F_{s m}^{p e s}+W F_{s m}^{m o s}}{2}\right)\right\} X_{s m t} \\
& R M \leq \sum_{s=1}^{S} \sum_{m=1}^{M} \sum_{t=1}^{T}\left\{\alpha\left(\frac{R M_{s m}^{p e s}+R M_{s m}^{m o s}}{2}\right)+(1-\alpha)\left(\frac{R M_{s m}^{o p t}+R M_{s m}^{m o s}}{2}\right)\right\} X_{s m t} \\
& S W^{c a p} \geq \sum_{s=1}^{S} \sum_{m=1}^{M} \sum_{t=1}^{T}\left\{\alpha\left(\frac{S W_{s m}^{o p t}+S W_{s m}^{m o s}}{2}\right)+(1-\alpha)\left(\frac{S W_{s m}^{p e s}+S W_{s m}^{m o s}}{2}\right)\right\} X_{s m t} \\
& L W^{\text {cap }} \geq \sum_{s=1}^{S} \sum_{m=1}^{M} \sum_{t=1}^{T}\left\{\alpha\left(\frac{L W_{s m}^{o p t}+L W_{s m}^{m o s}}{2}\right)+(1-\alpha)\left(\frac{L W_{s m}^{p e s}+L W_{s m}^{m o s}}{2}\right)\right\} X_{s m t} \\
& X_{s m t} \geq 0 \quad \forall s, m, t \\
& Z_{s t} \in\{0,1\} \forall s, t
\end{aligned}
$$

\section{Case study}

Suppose ABC company operates in the XYZ market. Recently, the company faces significant pressure from rivals regarding implementing sustainability measures. In this situation, the company wants to benchmark its operations as per the rival's strategy. Hence, the company intends to implement sustainability measures to its procurement decision. They emphasize on reducing the environmental footprint and enhancing its social image across its supply chain. To achieve this, the management has decided to procure raw material from environmentally and socially sustainable suppliers. However, the main challenge was identifying the social factors and how to use those factors for decision making.

The management has set up a committee and performed a brainstorming session to identify social sustainability issues. As social factors are subjective in nature, they could not be used in the traditional lotsizing model directly. Hence, there is a need to transfer the qualitative factors into quantitative scores for meaningful decisions. The management was thinking of applying the BWM-TOPSIS method to calculate the social ratings of suppliers. The detailed calculations are discussed below.

\section{Stage 1 calculation}

The first stage to select and quantify the potential social factors from the identified range of factors. Initially, 12 factors have been identified from the archived literature. Further, these factors have been reduced to 
eight by taking the opinions of academic and industry experts, shown in Table 2. In this study, we have contacted procurement managers having experience of more than five years.

Table 2. Identified social sustainability factors

\begin{tabular}{|c|c|c|c|c|}
\hline SN & Factors & Code & Short description & Source \\
\hline 1 & Discrimination & $\mathrm{CR}_{1}$ & $\begin{array}{l}\text { It is a kind of practice to grant or deny } \\
\text { privileges based on their categorical } \\
\text { background }\end{array}$ & $\begin{array}{l}\text { (Winter and Lasch, } \\
\text { 2016; Das and Shaw, } \\
\text { 2017) }\end{array}$ \\
\hline 2 & Child labor & $\mathrm{CR}_{2}$ & $\begin{array}{l}\text { People working in organizations under the } \\
\text { age of } 18 \text { are defined as child labor. }\end{array}$ & $\begin{array}{l}\text { (Memari et al., 2019; } \\
\text { Hendiani et al. 2020) }\end{array}$ \\
\hline 3 & $\begin{array}{l}\text { Long working } \\
\text { hours }\end{array}$ & $\mathrm{CR}_{3}$ & $\begin{array}{l}\text { Prolonged working hours and continuous } \\
\text { workers activity in an organization. }\end{array}$ & $\begin{array}{l}\text { (Winter and Lasch, } \\
\text { 2016; Das and Shaw, } \\
\text { 2017) }\end{array}$ \\
\hline 4 & Compensation & $\mathrm{CR}_{4}$ & $\begin{array}{l}\text { Compensation is a kind of practice to pay } \\
\text { employees in terms of financial and non- } \\
\text { financial support for their services. }\end{array}$ & $\begin{array}{l}\text { (Winter and Lasch, } \\
\text { 2016; Das and Shaw, } \\
\text { 2017) }\end{array}$ \\
\hline 5 & $\begin{array}{l}\text { Freedom of } \\
\text { association }\end{array}$ & $\mathrm{CR}_{5}$ & $\begin{array}{l}\text { workers and employees to have a trade } \\
\text { union and freedom of assembly for their } \\
\text { collective bargaining. }\end{array}$ & $\begin{array}{l}\text { (Jain and Singh, } \\
\text { 2020) }\end{array}$ \\
\hline 6 & Health and safety & $\mathrm{CR}_{6}$ & $\begin{array}{l}\text { It is a set of rules designed to protect } \\
\text { employees from unnecessary accidents. }\end{array}$ & $\begin{array}{l}\text { (Bai et al. 2019; Yu et } \\
\text { al. 2019; Lahri 2020) }\end{array}$ \\
\hline 7 & $\begin{array}{l}\text { Information } \\
\text { disclosure/ } \\
\text { transparency }\end{array}$ & $\mathrm{CR}_{7}$ & $\begin{array}{l}\text { The transparent exchange of information } \\
\text { between the organizations, stakeholders, } \\
\text { and customers. }\end{array}$ & $\begin{array}{l}\text { (Mohammed et al., } \\
\text { 2019; Venkatesh et } \\
\text { al. 2020) }\end{array}$ \\
\hline 8 & $\begin{array}{l}\text { Training and } \\
\text { education }\end{array}$ & $\mathrm{CR}_{8}$ & $\begin{array}{l}\text { Training and education can be defined as the } \\
\text { transfer of knowledge and experiences } \\
\text { within and outside the organizations from } \\
\text { the employer within which they work }\end{array}$ & $\begin{array}{l}\text { (Bai et al. 2019; } \\
\text { Hendiani et al. 2020) }\end{array}$ \\
\hline
\end{tabular}

To compute the weights of the criteria, the BWM method has been applied. The industry experts were asked to choose the best and the worst criteria among eight finalized criteria, i.e., discrimination, child labor, long working hours, compensation, freedom of association, health and safety, information disclosure, and training and education. The experts have identified discrimination $\left(\mathrm{C}_{1}\right)$ as the best and Long working hours $\left(\mathrm{C}_{3}\right)$ as the worst criteria, among other social criteria. In this study, we have taken modal value for calculation. The value has been taken to avoid the fuzzy scenario.

Table 3 shows the best-to-others vector $A_{B}=(1,3,4,5,2,8,3,5)$. Similarly, other to worst vector is shown in

Table 4 as $A_{W}=(4,3,1,5,6,5,3,6)^{T}$.

Table 3. Best-to-others social vector.

\begin{tabular}{lllllllll}
\hline Criteria & $\mathrm{CR}_{1}$ & $\mathrm{CR}_{2}$ & $\mathrm{CR}_{3}$ & $\mathrm{CR}_{4}$ & $\mathrm{CR}_{5}$ & $\mathrm{CR}_{6}$ & $\mathrm{CR}_{7}$ & $\mathrm{CR}_{8}$ \\
\hline Best criterion $\left(\mathrm{C}_{1}\right)$ & 1 & 3 & 4 & 5 & 2 & 8 & 3 & 5 \\
\hline
\end{tabular}

Table 4. Others-to-worst vector

\begin{tabular}{cc}
\hline Other social criteria & Worst criteria: long working hours $\left(\mathrm{C}_{3}\right)$ \\
\hline $\mathrm{CR}_{1}$ & 4 \\
\hline
\end{tabular}




\begin{tabular}{ll}
$\mathrm{CR}_{2}$ & 3 \\
$\mathrm{CR}_{3}$ & 1 \\
$\mathrm{CR}_{4}$ & 5 \\
$\mathrm{CR}_{5}$ & 6 \\
$\mathrm{CR}_{6}$ & 5 \\
$\mathrm{CR}_{7}$ & 3 \\
$\mathrm{CR}_{8}$ & 6 \\
\hline
\end{tabular}

In this study, a linear programming model was developed using these vectors, best to others and others to worst. The final weights of the factors can be calculated from the linear programming model. The model was solved in LINGO 10 Optimization software. The results are illustrated in Table 5.

$$
\begin{aligned}
& \min =\varphi^{*} \\
& \text { s.t. }\left\{\begin{array}{l}
C R_{1}-3 * C R_{2} \leq \varphi \\
C R_{1}-4 * C R_{3} \leq \varphi \\
C R_{1}-5 * C R_{4} \leq \varphi \\
C R_{1}-2 * C R_{5} \leq \varphi \\
C R_{1}-8 * C R_{6} \leq \varphi \\
C R_{1}-3 * C R_{7} \leq \varphi \\
C R_{1}-5 * C R_{8} \leq \varphi \\
C R_{1}-4 * C R_{3} \leq \varphi \\
C R_{2}-3 * C R_{3} \leq \varphi \\
C R_{4}-5 * C R_{3} \leq \varphi \\
C R_{5}-6 * C R_{3} \leq \varphi \\
C R_{6}-5 * C R_{3} \leq \varphi \\
C R_{7}-3 * C R_{3} \leq \varphi \\
C R_{8}-6 * C R_{3} \leq \varphi \\
C R_{1}+C R_{2}+C R_{3}+C R_{4}+C R_{5}+C R_{6}+C R_{7}+C R_{8}=1 \\
C R_{1} \geq 0 ; C R_{2} \geq 0 ; C R_{3} \geq 0 ; C R_{4} \geq 0 ; C R_{5} \geq 0 ; C R_{6} \geq 0 ; C R_{7} \geq 0 ; C R_{8} \geq 0
\end{array}\right.
\end{aligned}
$$

Table 5. Optimal weights for social factors.

\begin{tabular}{lcc}
\hline Criteria & Weights score $\left(\mathrm{W}_{\mathrm{n}}{ }^{*}\right)$ & $\left(\varphi^{*}\right)$ \\
\hline Discrimination & 0.275 & 0.1324 \\
\hline Child / Forced labor & 0.136 & \\
Long working hours & 0.036 \\
Compensation & 0.081 \\
Freedom of association & 0.204 \\
Health and Safety & 0.051 \\
Information disclosure / Transparency & 0.136 \\
Training and education & 0.081 \\
\hline
\end{tabular}

In this study, discrimination has appeared as the utmost vital factor, followed by freedom of association, child labor, and information disclosure. Once the optimal weights of criteria were estimated, the consistency level of the comparison was checked by estimating the consistency ratio (Rezaei 2015). The consistency ratio for the problem mentioned above is $0.1324 / 4.47=0.029$, which imitates the findings of Rezaie (2015). 


$$
\text { Consistency Ratio }=\frac{\varphi^{*}}{\text { Consistency index }}
$$

Table 6. Consistency Index (Rezaei 2015)

\begin{tabular}{llllllllll}
\hline & 1 & 2 & 3 & 4 & 5 & 6 & 7 & 8 & 9 \\
\hline $\begin{array}{l}\text { Consistency } \\
\text { Index }\end{array}$ & 0.00 & 0.44 & 1.00 & 1.63 & 2.30 & 3.00 & 3.73 & 4.47 & 5.23 \\
\hline
\end{tabular}

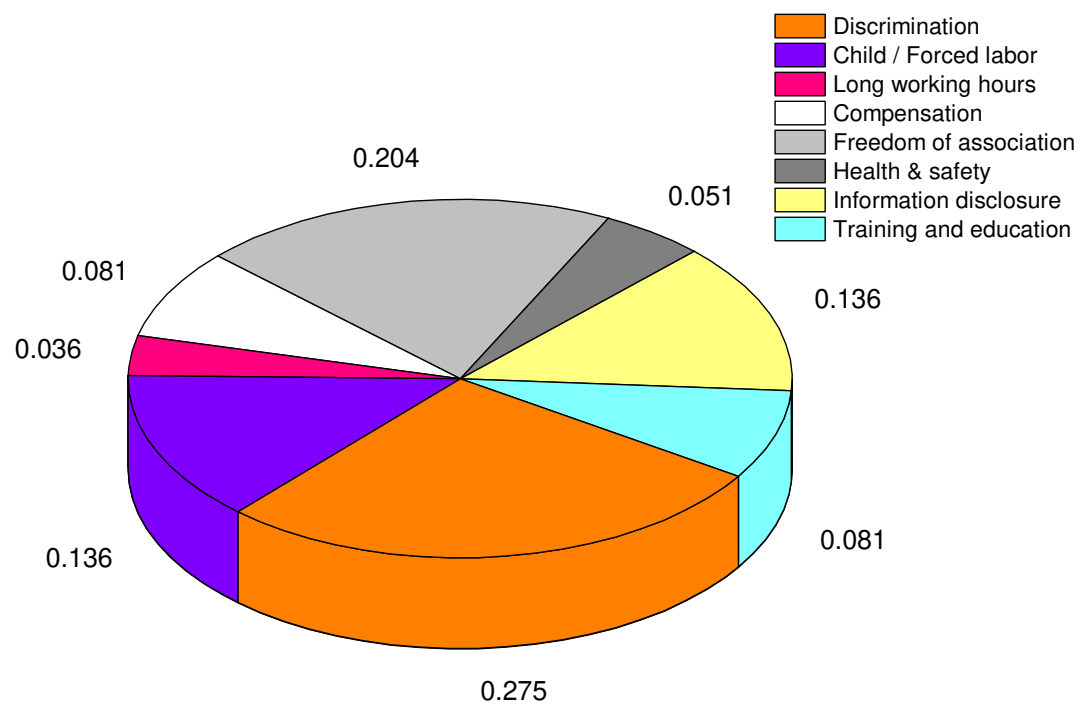

Figure 1. Weights of supplier's social criteria

The weights estimated by BWM have been further used in TOPSIS to rank the potential suppliers. In this study, we have applied a scale (1-10) to quantify the suppliers. In this study, 10 was allotted if the supplier performs the best and 1 if it performs the worst. The preference rating of suppliers with respect to social criteria is shown in Table 7. For preference rating calculations, we have taken random values. Subsequently, by applying steps 7 to 11 final ranking of suppliers was evaluated. The results are shown in Table 9. In this analysis, supplier 7 has emerged as the best supplier, followed by supplier 10, supplier 1 . After calculating the social weights, these can be used in the final lot-sizing algorithm to estimate the order size. In this study, the data was generalized randomly.

Table 7. Preference rating for suppliers.

\begin{tabular}{lllllllll}
\hline Suppliers & $\mathrm{CR}_{1}$ & $\mathrm{CR}_{2}$ & $\mathrm{CR}_{3}$ & $\mathrm{CR}_{4}$ & $\mathrm{CR}_{5}$ & $\mathrm{CR}_{6}$ & $\mathrm{CR}_{7}$ & $\mathrm{CR}_{8}$ \\
\hline $\mathrm{Sl}_{1}$ & 6 & 7 & 7 & 8 & 6 & 9 & 8 & 6 \\
$\mathrm{Sl}_{2}$ & 6 & 4 & 5 & 7 & 6 & 8 & 8 & 6 \\
$\mathrm{Sl}_{3}$ & 7 & 5 & 5 & 7 & 5 & 6 & 7 & 8 \\
$\mathrm{Sl}_{4}$ & 5 & 8 & 7 & 8 & 7 & 7 & 7 & 6 \\
$\mathrm{Sl}_{5}$ & 5 & 8 & 6 & 8 & 6 & 5 & 8 & 6 \\
$\mathrm{Sl}_{6}$ & 4 & 7 & 5 & 7 & 7 & 6 & 6 & 7 \\
$\mathrm{Sl}_{7}$ & 7 & 6 & 7 & 6 & 7 & 8 & 7 & 6 \\
$\mathrm{Sl}_{8}$ & 6 & 8 & 7 & 8 & 6 & 7 & 5 & 8 \\
$\mathrm{Sl}_{9}$ & 7 & 5 & 6 & 7 & 7 & 6 & 5 & 7 \\
$\mathrm{Sl}_{10}$ & 7 & 5 & 5 & 7 & 7 & 6 & 7 & 8 \\
\hline
\end{tabular}


Table 8. Weighted normalized decision matrix.

\begin{tabular}{cllllllll}
\hline Suppliers & $\mathrm{CR}_{1}$ & $\mathrm{CR}_{2}$ & $\mathrm{CR}_{3}$ & $\mathrm{CR}_{4}$ & $\mathrm{CR}_{5}$ & $\mathrm{CR}_{6}$ & $\mathrm{CR}_{7}$ & $\mathrm{CR}_{8}$ \\
\hline $\mathrm{Sl}_{1}$ & 0.086 & 0.047 & 0.013 & 0.028 & 0.060 & 0.021 & 0.050 & 0.022 \\
$\mathrm{Sl}_{2}$ & 0.086 & 0.027 & 0.009 & 0.024 & 0.060 & 0.019 & 0.050 & 0.022 \\
$\mathrm{Sl}_{3}$ & 0.100 & 0.033 & 0.009 & 0.024 & 0.050 & 0.014 & 0.044 & 0.030 \\
$\mathrm{Sl}_{4}$ & 0.071 & 0.053 & 0.013 & 0.028 & 0.070 & 0.016 & 0.044 & 0.022 \\
$\mathrm{Sl}_{5}$ & 0.071 & 0.053 & 0.011 & 0.028 & 0.060 & 0.012 & 0.050 & 0.022 \\
$\mathrm{Sl}_{6}$ & 0.057 & 0.047 & 0.009 & 0.024 & 0.070 & 0.014 & 0.037 & 0.026 \\
$\mathrm{Sl}_{7}$ & 0.100 & 0.040 & 0.013 & 0.021 & 0.070 & 0.019 & 0.044 & 0.022 \\
$\mathrm{Sl}_{8}$ & 0.086 & 0.053 & 0.013 & 0.028 & 0.060 & 0.016 & 0.031 & 0.030 \\
$\mathrm{Sl}_{9}$ & 0.100 & 0.033 & 0.011 & 0.024 & 0.070 & 0.014 & 0.031 & 0.026 \\
$\mathrm{Sl}_{10}$ & 0.100 & 0.033 & 0.009 & 0.024 & 0.070 & 0.014 & 0.044 & 0.030 \\
\hline
\end{tabular}

Table 9. Social score of suppliers.

\begin{tabular}{cccc}
\hline Suppliers & $K_{n}^{+}$ & $K_{n}^{-}$ & $\tilde{S} S_{S}$ \\
\hline $\mathrm{Sl}_{1}$ & 0.000405 & 0.001819 & 0.82 \\
$\mathrm{Sl}_{2}$ & 0.001102 & 0.001331 & 0.55 \\
$\mathrm{Sl}_{3}$ & 0.000916 & 0.002113 & 0.70 \\
$\mathrm{Sl}_{4}$ & 0.000934 & 0.001557 & 0.62 \\
$\mathrm{Sl}_{5}$ & 0.001065 & 0.001418 & 0.57 \\
$\mathrm{Sl}_{6}$ & 0.002129 & 0.000872 & 0.29 \\
$\mathrm{Sl}_{7}$ & 0.000327 & 0.002638 & 0.89 \\
$\mathrm{Sl}_{8}$ & 0.000678 & 0.001768 & 0.72 \\
$\mathrm{Sl}_{9}$ & 0.000829 & 0.002321 & 0.74 \\
$\mathrm{Sl}_{10}$ & 0.000514 & 0.002516 & 0.83 \\
\hline
\end{tabular}

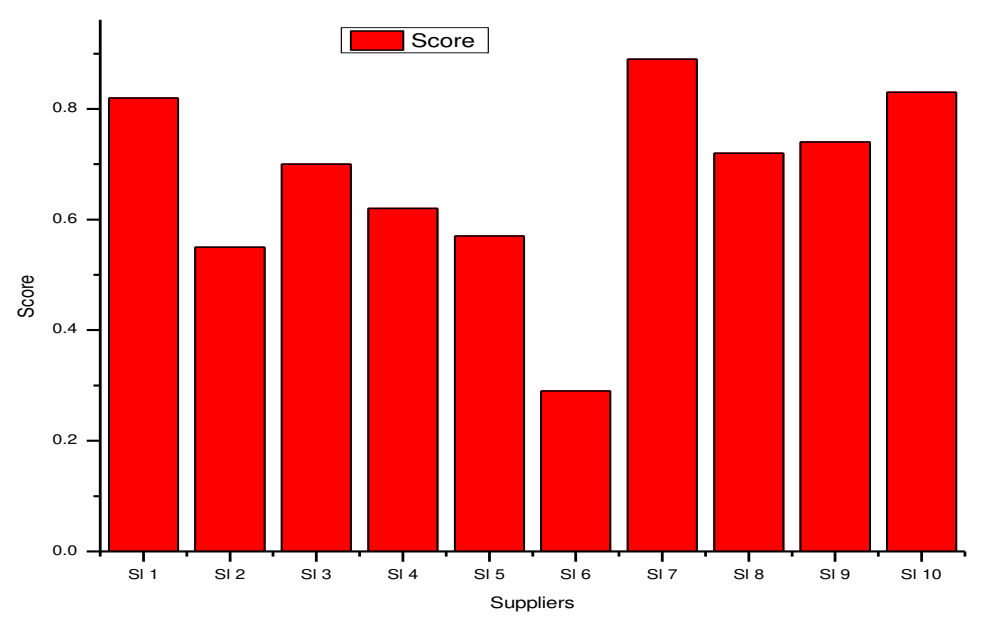

Figure 2. Ranking of potential sustainable suppliers

\section{Stage 2 calculation}

To get the possibilistic distribution of the model variables, the generated data were shared with the supply chain managers. The data were categorized into three segments (pessimistic, most likely, and optimistic). The fuzzy data for product cost is presented in Appendix (Table A.1). In this experiment, initially, the most 
likely $\left(\phi^{\text {mos }}\right)$ value for each ambiguous parameter was generated randomly. Then, the Pessimistic $\left(\phi^{\text {pes }}\right)$ and optimistic $\left(\phi^{o p t}\right)$ values of a fuzzy number $\left(\tilde{\phi}_{i j}\right)$ were calculated as follows:

$\phi_{i j}^{p e s}=\left(1-\theta^{L T}\right) \cdot \phi_{i j}^{m o s}$ and $\phi_{i j}^{o p t}=\left(1+\theta^{R T}\right) \cdot \phi_{i j}^{m o s}$,

Where $\theta^{L T}$ and $\theta^{R T}$ are left and right-side percentages. The deviation was considered $25 \%$ based on the previous similar study (Bouzembrak et al. 2013).

All the cost data are expressed in Indian rupee (₹), while carbon emission is taken in Kilograms (Kg). To analyze the computational performance, a code was written in Lingo 10 optimization software using a laptop pc having $2.6 \mathrm{GHz}$ and $8 \mathrm{~GB}$ RAM. We have determined the minimum acceptable feasibility degree $(\alpha)$, taking reference toa similar study (Lahri et al. 2020). The model was tested for different feasibility degrees $(\alpha=0.4,0.6,0,8$, and 0.9$)$ to assess the impacts of uncertainty. Also, for each $\alpha$-value, five Pareto optimal solutions (i.e., $0.4-0.8$ ) were generated using the modified $\varepsilon$-constraint method. In this study, the emission objective was kept in the main objective, while cost and social objectives were kept in the constraint, using $\varepsilon$-constraint theory. Initially, the model was tested considering 10 suppliers, 6 periods, and 6 products; this is called a base experiment, and the results are depicted in Table 10. The model can be solved in finite time, approximately 1 to 3 seconds for the base experiment. Table 10 shows the results of the lot-sizing model at different $\alpha$ and $\varepsilon$ values.

Results show that granting a higher $\varepsilon$ value in the constraints at a particular feasibility degree $(\alpha)$ leads to the moderate attainment of the environmental objective. In contrast, the social objective is achieved with a higher value. In this experiment, no feasible solutions were found when $\varepsilon$ value is greater than equal to 0.8 . Minimum total cost is achieved at $(\alpha=0.9$ and $\varepsilon=0.7)$ and minimum carbon emission found at $(\alpha$ $=0.9$ and $\varepsilon=0.4)$. Similarly, maximum social sustainability realized at $(\alpha=0.4$ and $\varepsilon=0.7)$ for the proposed lot-sizing problem. The results are shown in Table 10 reveal that increasing achievement of social sustainability objective restricts the achievement of emission goal.

Table 10. Results for 10 suppliers, 6 time periods, and 6 products.

\begin{tabular}{|c|c|c|c|c|c|c|c|c|c|c|c|c|c|}
\hline \multicolumn{4}{|c|}{ Primary goals } & \multicolumn{6}{|c|}{ Cost functions } & \multicolumn{4}{|c|}{ Emission functions } \\
\hline$\alpha \quad \varepsilon$ & $\mathrm{TC}$ & TE & SS & $\mathrm{OC}$ & $\mathrm{PC}$ & PTAX & TRC & $\mathrm{HC}$ & IHC & PEMI & TEMI & IEMI & $\mathrm{T}$ \\
\hline 0.40 .4 & 92695470 & 1043255 & 215762.8 & 194769.5 & 5724346 & 18451630 & 16069 & 2224743 & 231267.3 & 1026686 & 13392.7 & 3176.36 & .1 \\
\hline 0.40 .5 & 105967200 & 1150706 & 238600.2 & 193602 & 798856 & 23841990 & 118274 & 224827.3 & 638412.3 & 1128015 & 13647.13 & 39044.005 & 0.2 \\
\hline 0.40 .6 & 95583510 & 1731209 & 261437.6 & 193323 & 801080 & 12710260 & 117203 & 218916.8 & 1180973 & 1701238 & 13523.58 & 816447.36 & 0.1 \\
\hline 0.40 .7 & 84002010 & 3039831 & 284275.1 & 197442 & 672069 & 13712290 & 123573 & 230176.5 & 1419389 & 3006494 & 14258.55 & 519078.19 & 0.1 \\
\hline 0.40 .8 & 0 & 0 & 0 & 0 & 0 & 0 & 0 & 0 & 0 & 0 & 0 & 0 & \\
\hline
\end{tabular}



0.60 .51026732001119664231220 .619597077628060229080101150894224101 .5566138 .7109833813279 .68046 .7570 .1 0.60 .6925572401663900252253 .919332377477880125496201172032218916 .8945463 .5163716813523 .5813208 .130 .1 0.60 .7817757902850000273287 .219744265346170135489201235732230176 .51217351281903214258 .5516709 .470 .1

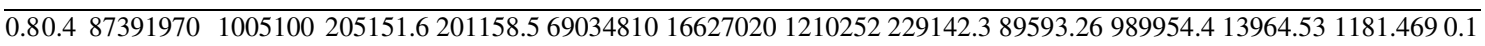
0.80 .5998142401092407224516 .119597075493630222840301150894224101 .5465606 .1107249913279 .66629 .0340 .2 0.80 .6897737501607917243880 .5199201 .275202200120580801222030227239 .8864997 .3158189914100 .4811917 .940 .1 0.80 .7797332602696425263244 .919744263795810133119401235732230176 .5962156 .1266898514258 .5513181 .820 .1 $\overline{0.90 .486334730997360 .9202814 .1201158 .568291280163118401210252229142 .291056 .31982154 .413964 .531241 .9490 .1}$ 0.90 .5981471601080247221389 .1201433 .374698160213013701222212230361 .5493624 .2105909214102 .537052 .4340 .1 0.90 .6884588501582977239964 .1199201 .274055550119828001222030227239 .8772029 .3155831114100 .4810565 .290 .1 0.90 .7787705402629734258539 .1205080 .262770090133536601264982237113 .5939616260159414596 .0513544 .450 .2

Note: $\mathrm{TC}=$ total cost (Rs.), $\mathrm{TE}=$ total emission $(\mathrm{Kg}), \mathrm{SS}=$ social sustainability, OC = ordering cost (Rs.), $\mathrm{PC}=$ purchasing cost (Rs.), PTAX = purchasing tax (Rs.), TRC = transportation cost (Rs.), HC = handling cost (Rs.), IHC = inventory holding cost (Rs.), PEMI = product emission $(\mathrm{Kg})$, TEMI = transportation emission $(\mathrm{Kg}), \mathrm{IEMI}=$ inventory emission $(\mathrm{Kg}) . \mathrm{T}=$ time $(\mathrm{sec}$
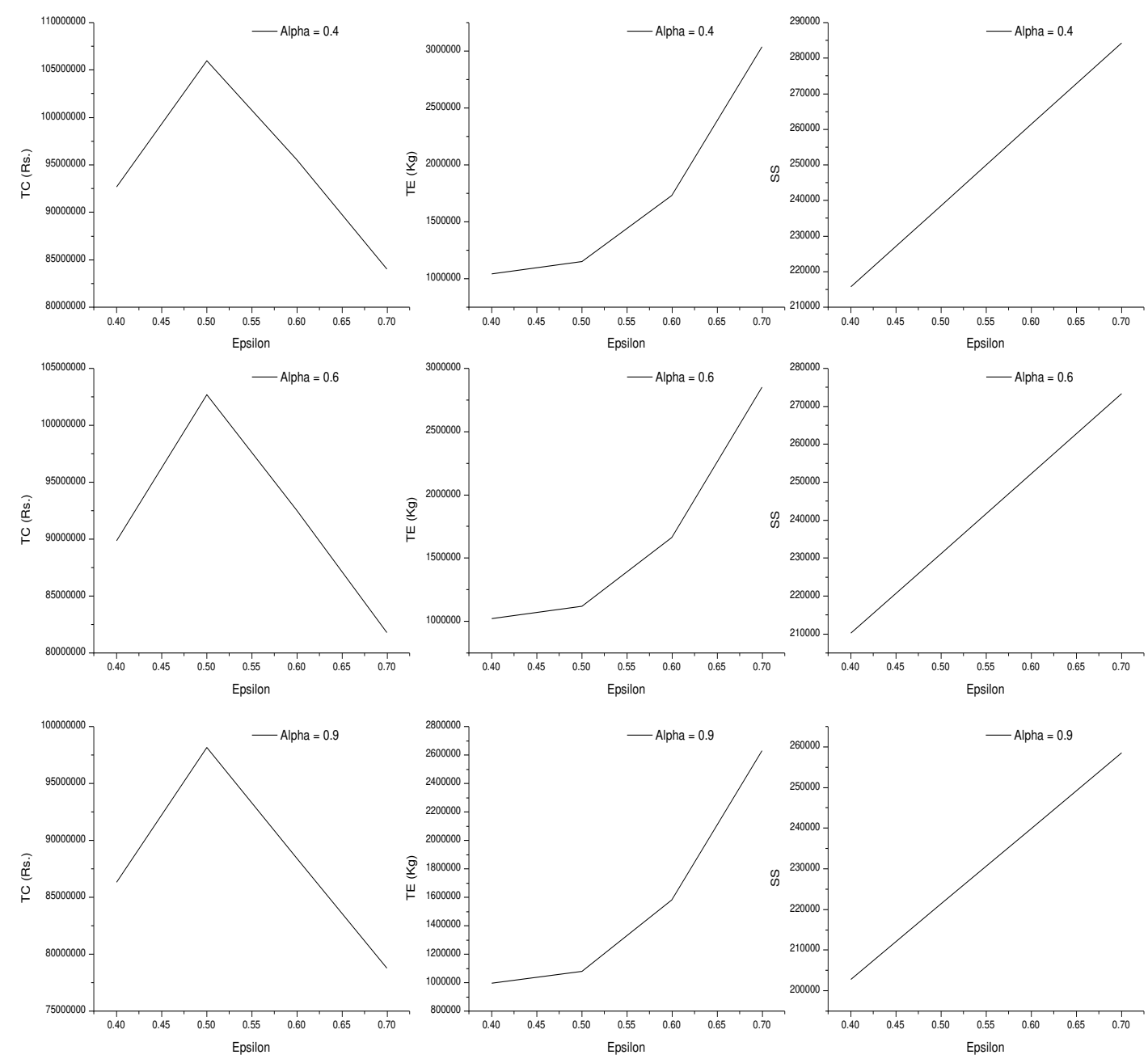

Figure 3. Sensitivity analysis of TC, TE, and SS by changing $\varepsilon$ value at distinct $\alpha$ setting. 
Figure 3 illustrates the sensitivity analysis of TC, TE, and SS at distinct $\varepsilon$ values from a range of 0.4 to 0.7. The model provides no solution when the $\varepsilon$ value is greater than or equal to 0.8 . It can be observed from Fig. 3 that the graph follows an almost similar distribution curve, for instance $(\alpha=0.4,0.6$, and 0.9$)$. However, the obtained values of the three goals are different. In this study, the emission goal is maximized subjected to cost and social goal in the constraint. When $\varepsilon$ value increases from 0.4 to 0.7 , a restriction is imposed on the cost and social goal, which resulted in the lower achievement of the emission goal. Hence with increasing the $\varepsilon$ value, the overall emission of the supply chain increases. An interesting phenomenon was observed from the results. The results show that cost of the supply chain can be reduced with increasing social scores. For example, a more orientation on a social issue can help reduce the overall costs of the supply chain.
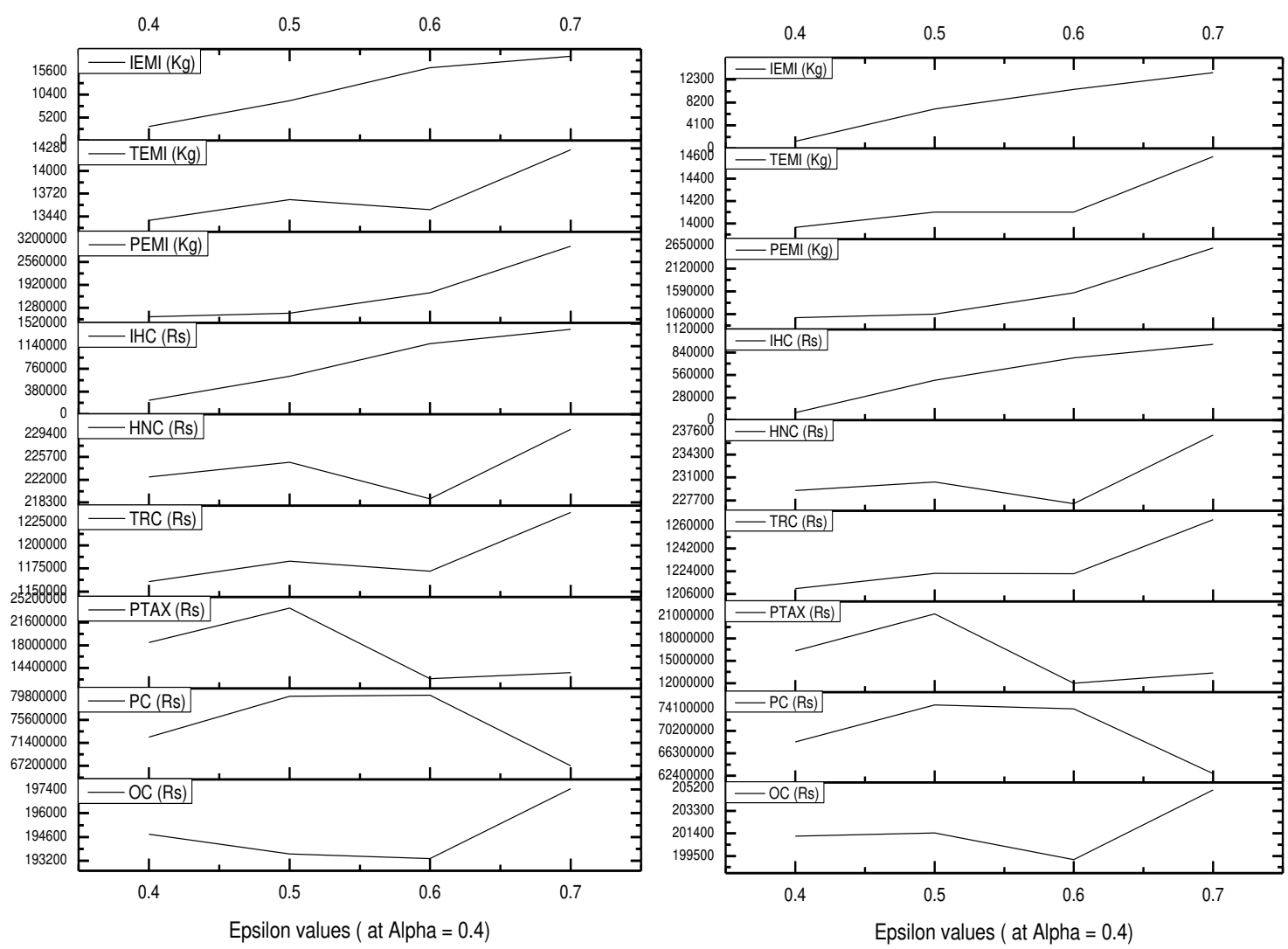

Figure 4. Sensitivity analysis cost and emission parameters by changing $\varepsilon$ value at different $\alpha$ values.

Figure 4 shows a broader spectrum of different costs (i.e., ordering cost, purchasing cost, purchasing tax, transportation cost, handling cost, inventory cost), different emissions (such as product emission, transportation emission, and inventory emission) associated with the lot-sizing problem. It can be observed from the figure that there is a considerable variation in purchasing tax (PTAX) and Holding cost (IHC) and a slight change in other costs with changing $\varepsilon$ values. Similarly, with changing $\varepsilon$ values, higher variation 
was found in the product emission (PEMI) and inventory emission (IEMI), respectively. From these graphs, managers can analyze the impact of different costs and emissions and their behavior with different uncertain levels in the lot-sizing problem. Subsequently, they can develop their strategy.

Table 11. Optimal selection of supplier and lot sizing $(\alpha=0.9$ and $\varepsilon=0.7)$

\begin{tabular}{|c|c|c|c|c|c|c|c|}
\hline Product & PR 1 & PR 2 & PR 3 & PR 4 & PR 5 & PR 6 & Period \\
\hline \multirow{6}{*}{ Supplier 1} & 185 & 4322 & 0 & 0 & 193 & 5292 & TP 1 \\
\hline & 0 & 0 & 0 & 0 & 6398 & 5111 & TP 2 \\
\hline & 0 & 0 & 0 & 0 & 351 & 9032 & TP 3 \\
\hline & 0 & 560 & 0 & 0 & 5150 & 5163 & TP 4 \\
\hline & 0 & 0 & 0 & 0 & 3895 & 9298 & TP 5 \\
\hline & 0 & 0 & 0 & 0 & 7723 & 1285 & TP 6 \\
\hline \multirow{6}{*}{ Supplier 3} & 7811 & 0 & 5522 & 69 & 0 & 0 & TP 1 \\
\hline & 5133 & 4147 & 732 & 65 & 0 & 0 & TP 2 \\
\hline & 7671 & 1488 & 148 & 60 & 0 & 0 & TP 3 \\
\hline & 6916 & 4408 & 1606 & 0 & 0 & 0 & TP 4 \\
\hline & 5927 & 1592 & 2982 & 0 & 0 & 0 & TP 5 \\
\hline & 6909 & 0 & 6107 & 0 & 0 & 0 & TP 6 \\
\hline Supplier 4 & 104 & 0 & 8374 & 0 & 0 & 0 & TP 6 \\
\hline \multirow{6}{*}{ Supplier 7} & 0 & 1022 & 1946 & 6232 & 0 & 0 & TP 1 \\
\hline & 0 & 3593 & 0 & 5842 & 0 & 0 & TP 2 \\
\hline & 0 & 448 & 0 & 5382 & 0 & 6872 & TP 3 \\
\hline & 0 & 0 & 0 & 8856 & 0 & 3037 & TP 4 \\
\hline & 0 & 1627 & 0 & 8059 & 0 & 0 & TP 5 \\
\hline & 0 & 3249 & 0 & 8481 & 0 & 0 & TP 6 \\
\hline \multirow{5}{*}{ Supplier 8} & 119 & 1533 & 4682 & 0 & 0 & 0 & TP 2 \\
\hline & 478 & 3546 & 7873 & 0 & 0 & 0 & TP 3 \\
\hline & 0 & 3522 & 5542 & 0 & 0 & 0 & TP 4 \\
\hline & 0 & 4601 & 5121 & 0 & 0 & 0 & TP 5 \\
\hline & 59 & 3144 & 8374 & 0 & 0 & 0 & TP 6 \\
\hline Supplier 9 & 0 & 0 & 0 & 8481 & 0 & 0 & TP 6 \\
\hline \multirow{6}{*}{ Supplier 10} & 0 & 0 & 0 & 0 & 6623 & 2549 & TP 1 \\
\hline & 0 & 0 & 0 & 0 & 6398 & 3742 & TP 2 \\
\hline & 0 & 0 & 0 & 0 & 8825 & 2308 & TP 3 \\
\hline & 0 & 0 & 55 & 188 & 5150 & 5163 & TP 4 \\
\hline & 0 & 0 & 0 & 0 & 9257 & 3266 & TP 5 \\
\hline & 0 & 0 & 0 & 0 & 7723 & 3250 & TP 6 \\
\hline \multirow{6}{*}{ Inventory } & - & - & - & - & - & 2365 & TP 1 \\
\hline & - & - & - & - & 6047 & 4808 & TP 2 \\
\hline & 296 & 101 & & - & 6138 & 13563 & TP 3 \\
\hline & 136 & - & 1525 & 88 & 11005 & 21488 & TP 4 \\
\hline & - & 2081 & 4352 & - & 14534 & 24448 & TP 5 \\
\hline & - & - & 18455 & 8210 & 21833 & 22869 & TP 6 \\
\hline
\end{tabular}

Table 11 represents the results of the lot-sizing problem to meet six products' demands for periods 1 to 6 .

From the results, it can be observed that suppliers $1,3,4,7,8,9$, and 10 are preferred to satisfy the demands 
across the entire period. However, suppliers 4 and 9 were least preferred, and Suppliers 2 and 6 were not preferred due to the lowest sustainability score. It shows that our proposed sustainable lot-sizing model is useful and only chooses suppliers having the highest scores. The demand for product 1 is satisfied by suppliers 1, 3, 4, and 8. Similarly, the demand for product 2 fulfilled by suppliers 1, 3, 7, and 8. Likewise, all the demand for different products is satisfied by the corresponding potential suppliers across the entire period. Table 11 also shows the inventory of the products across the period.

\subsection{Sensitivity analysis by changing $\mu 1, \mu 2$, and $\mu 3$, individually, in the objective function.}

The emission goal has been maximized in the earlier section, keeping cost and social sustainability goals in the constraint. However, it would be exciting to examine the behavior of the model by solving specific goals separately.

Table 12. Solutions of the model at different scenarios.

\begin{tabular}{llll}
\hline Goals (at $\alpha=0.9$ and $\varepsilon=0.7)$ & $\begin{array}{l}\text { Max } \mu_{1} \text { without } \\
\text { considering } \mu_{2} \text { and }\end{array}$ & $\begin{array}{l}\text { Max } \mu_{2} \text { without } \\
\text { considering } \mu_{1} \text { and } \\
\mu_{3}\end{array}$ & $\begin{array}{l}\text { Max } \mu 3 \text { without } \\
\text { considering } \mu_{1} \\
\text { and } \mu_{2}\end{array}$ \\
\hline Economic sustainability (Rs.) & 49705620 & 90968900 & 122912500 \\
Environment sustainability (Kg) & 2568921 & 945245.2 & 2778523 \\
Social sustainability & 168517.8 & 169285.5 & 314264.4 \\
\hline
\end{tabular}

The results in Table 12 show that maximizing the membership function of the goal alone can lead to a higher realization of that goal. For instance, initially, $\mu 1$ is maximized by excluding $\mu 2$ and $\mu 3$ from the constraint. Further, $\mu 2$ is maximized in the objective function without considering the $\mu 1$ and $\mu 3$. Likewise, $\mu 3$ maximized in the objective function without considering $\mu 1$ and $\mu 2$.

Table 13. Results for 35 suppliers, 12 time periods, and 10 products.

\begin{tabular}{llllll}
\hline & & \multicolumn{4}{c}{ Objective functions } \\
\cline { 3 - 5 }$\alpha$ - value & $\varepsilon-$ value & Total cost & Total emission & $\begin{array}{l}\text { Social } \\
\text { sustainability }\end{array}$ & Time \\
\hline 0.4 & 0.6 & 407006100 & 3777332 & 749743.9 & 5.40 Hrs. \\
0.4 & 0.8 & 467634800 & 4633292 & 1051695 & 4.35 Hrs. \\
0.4 & 0.9 & 0 & 00 & 0 & No solution \\
\hline 0.6 & 0.4 & 404000000 & 3802379 & 719655.5 & 4.5 Hrs. \\
0.6 & 0.6 & 444000000 & 4411549 & 1006165 & 90 min \\
0.6 & 0.8 & 0 & 0 & 0 & No solution \\
\hline 0.8 & 0.4 & 410319400 & 3804665 & 709361.8 & 5.3 Hrs. \\
0.8 & 0.6 & 420459900 & 4215400 & 964277.4 & 18.44 min \\
0.8 & 0.8 & 0 & 0 & 0 & No solution \\
\hline
\end{tabular}

In literature, the lot-sizing problem has been referred to as an NP-hard problem as it deals with a significant number of variables (Keshavarz Ghorabaee et al., 2017). Therefore, to check the proposed algorithm's complexity, it is essential to conduct experiments with bigger sample size. To achieve the goal, a set of 
experiments were performed by considering 35 suppliers, 10 products, and 12 time periods at different $\alpha$ and $\varepsilon$-values. The results of the experiments are depicted in Table 13. From the results, it can be observed that for an increasing data set, solution time was found to be increasing significantly. And for most cases, the algorithm can provide solutions in around 4-6 hours. On the other hand, the algorithm has been unable to provide feasible solutions in some cases. It may be due to explicit $\alpha$ and $\varepsilon$ values. For example, at $(\alpha=$ $0.4,0.6$ and $\varepsilon$-value $>0.9)$ and $(\alpha=0.8$ and $\varepsilon$-value $>0.8)$, the algorithm could not give feasible solution. The experiment also suggests that the model may be practical in a real-life situation.

\section{Conclusion}

The study proposes a multi-objective, multi-supplier, multi-item, multi-period lot-sizing problem considering carbon footprint, water footprint, solid waste, liquid waste, social sustainability under uncertain environment. Triple bottom line theory has been utilized in the presented study, where economic, environmental, and social sustainability are dealt simultaneously. The present study has been conducted in three stages. The social score of the suppliers is calculated using the combined BWM and TOPSIS method at the primary stage and TOPSIS has rarely been used to quantify the sustainability of suppliers in the literature. In the second stage, the suppliers' social scores are used in an uncertain lot-sizing model. Later, the uncertain model is transformed into an equivalent crisp model using a possibilistic programming approach. In the third stage, different trade-off curves are generated by the application of the e-constraint method. The proposed model has successfully controlled conflicting objectives, such as cost, carbon emission, and social sustainability. The present study examines ambiguous scenarios by applying multiobjective possibilistic programming. In this research, the total carbon emissions were measured by taking into account product emissions, transport emissions, and inventory holding emissions.

The applicability of the model has been illustrated with a numerical example. Initially, ten suppliers with six periods and six products were considered. Further, to check the algorithm's complexity, 35 suppliers with 12 periods and 10 products were explored. The computational analysis of the model was carried out in LINGO 10 optimization software. The solution time of the algorithm confirms the applicability of the presented model.

The presented lot-sizing model helps managers to choose suitable suppliers for each product in each period. The results prove that considering sustainability issues in the lot-sizing problem can lead to a balanced procurement.

\section{Theoretical contribution}


A lot-sizing problem applying BWM, TOPSIS, possibilistic programming, and $\varepsilon$-constraint method together have not been reported in the achieved literature. The current study has extended the model of Shaw (2017), Kaur and Singh (2017), and Lamba et al. (2019) through incorporating social sustainability of supplier, water footprint, solid waste, liquid waste, and rejection rate in a multi-objective, multi-period, multi-product lot-sizing problem under uncertain business environment. The current study successfully proved that varying uncertainty and $\varepsilon$ value can influence the cost, emission as well as social sustainability. From the experiment, it can be conjectured that an increase in uncertainty $(\alpha)$ will increase the overall cost of the system. Our proposed model is of considerable importance to manufacturers and policy-makers. Any organization may adopt the proposed model to create cost-effective carbon management strategies. The decision-maker can determine the differentiation costs for the reduction of the environmental footprint and the improvement of social sustainability.

\section{Limitation of this study}

There are some limitations to this work, like other studies. For instance, in some cases, Lingo 10 could not deliver a feasible result for the model. Moreover, the model belongs to the NP-hard class, in which the solution time increased with increasing the data set. Therefore, in future research, the model's performance may be compared with commercially available software like GAMS, CPLEX, and AMPL; a new heuristics method can be formulated in this regard. Besides, the present study has applied a possibilistic programming approach that handles the uncertainty. However, it would be interesting to extend the model with a robust possibilistic programming approach in the future. 


\section{References}

Absi, N., Dauzère-Pérès, S., Kedad-Sidhoum, S., Penz, B., \& Rapine, C. (2016). The single-item green lotsizing problem with fixed carbon emissions. European Journal of Operational Research, 248(3), $849-855$.

Aissaoui, N., Haouari, M., \&Hassini, E. (2007). Supplier selection and order lot sizing modeling: A review. Computers \& operations research, 34(12), 3516-3540.

Alfares, H. K., \&Turnadi, R. (2018). Lot sizing and supplier selection with multiple items, multiple periods, quantity discounts, and backordering. Computers \& Industrial Engineering, 116, 59-71.

Amid, A., Ghodsypour, S. H., \& O’Brien, C. (2006). Fuzzy multi-objective linear model for supplier selection in a supply chain. International Journal of production economics, 104(2), 394-407.

Arrow, K.J., Karlin, S., Scarf, H. (Eds.), 1962. Studies in Applied Probability and Management Science. Stanford University Press, Stanford.

Arslan, M.C., Turkay, M., 2011. EOQ revisited with sustainability considerations. Working paper, Koç University, Istanbul, Turkey. http://home.ku.edu.tr/ mturkay/pub/EOQ_Sustainability.pdf.

Attila, Ö. N., Agra, A., Akartunalı, K., \&Arulselvan, A. (2020). Robust formulations for economic lotsizing problem with remanufacturing. European Journal of Operational Research, 288(2), 496510.

Azadnia, A. H., Saman, M. Z. M., \& Wong, K. Y. (2015). Sustainable supplier selection and order lotsizing: an integrated multi-objective decision-making process. International Journal of Production Research, 53(2), 383-408.

Bai, C., Kusi-Sarpong, S., Badri Ahmadi, H., \& Sarkis, J. (2019). Social sustainable supplier evaluation and selection: a group decision-support approach. International Journal of Production Research, 57(22), 7046-7067.

Ben-Daya, M., Darwish, M., \&Ertogral, K. (2008). The joint economic lot sizing problem: Review and extensions. European Journal of Operational Research, 185(2), 726-742.

Benjaafar, S., Li, Y., Daskin, M., (2010). Carbon footprint and the management of supply chains: insights from simple models. Working paper. University of Minnesota, Available from: http://www.isye.umn.edu/faculty/pdf/beyada-10-02-10-final.pdf. [Accessed 10 May 2011].

Benjaafar, S., Li, Y., \&Daskin, M. (2012). Carbon footprint and the management of supply chains: Insights from simple models. IEEE transactions on automation science and engineering, 10(1), 99-116. 
Bellman, R. E., \& Zadeh, L. A. (1970). Decision-making in a fuzzy environment. Management science, 17(4), B-141.

Bonney, M., \& Jaber, M. Y. (2011). Environmentally responsible inventory models: Non-classical models for a non-classical era. International Journal of Production Economics, 133(1), 43-53.

Bodaghi, G., Jolai, F., \& Rabbani, M. (2018). An integrated weighted fuzzy multi-objective model for supplier selection and order scheduling in a supply chain. International Journal of Production Research, 56(10), 3590-3614.

Bouzembrak, Y., Allaoui, H., Goncalves, G., Bouchriha, H., \&Baklouti, M. (2013). A possibilistic linear programming model for supply chain network design under uncertainty. IMA Journal of Management Mathematics, 24(2), 209-229.

Brahimi, N., Dauzère-Pérès, S., \&Najid, N. M. (2006). Capacitated multi-item lot-sizing problems with time windows. Operations Research, 54(5), 951-967.

Brandimarte, P. (2006). Multi-item capacitated lot-sizing with demand uncertainty. International Journal of Production Research, 44(15), 2997-3022.

Büyüktahtakın, İ. E., Smith, J. C., \& Hartman, J. C. (2018). Partial objective inequalities for the multi-item capacitated lot-sizing problem. Computers \& Operations Research, 91, 132-144.

Cárdenas-Barrón, L. E., González-Velarde, J. L., \&Treviño-Garza, G. (2015). A new approach to solve the multi-product multi-period inventory lot sizing with supplier selection problem. Computers \& Operations Research, 64, 225-232.

Cheraghalipour, A., Paydar, M. M., \&Hajiaghaei-Keshteli, M. (2018). Applying a hybrid BWM-VIKOR approach to supplier selection: a case study in the Iranian agricultural implements industry. International Journal of Applied Decision Sciences, 11(3), 274-301.

Chen, X., Benjaafar, S., \&Elomri, A. (2013). The carbon-constrained EOQ. Operations Research Letters, 41(2), 172-179. downloaded from: http://www.isye.umn.edu/faculty/pdf/cbe-2011.pdf.

Chiou, T. Y., Chan, H. K., Lettice, F., \& Chung, S. H. (2011). The influence of greening the suppliers and green innovation on environmental performance and competitive advantage in Taiwan. Transportation Research Part E: Logistics and Transportation Review, 47(6), 822-836.

Choudhary, D., \& Shankar, R. (2011). Modeling and analysis of single item multi-period procurement lotsizing problem considering rejections and late deliveries. Computers \& Industrial Engineering, 61(4), 1318-1323. 
Čuček, L., Klemeš, J. J., \&Kravanja, Z. (2012). A review of footprint analysis tools for monitoring impacts on sustainability. Journal of Cleaner Production, 34, 9-20.

Das, R., \& Shaw, K. (2017). Uncertain supply chain network design considering carbon footprint and social factors using two-stage approach. Clean Technologies and Environmental Policy, 19(10), 24912519.

Das, R., Shaw, K., \& Irfan, M. (2020). Supply chain network design considering carbon footprint, water footprint, supplier's social risk, solid waste, and service level under the uncertain condition. Clean Technologies and Environmental Policy, 22(2), 337-370.

Delgado, M., Verdegay, J. L., \& Vila, M. A. (1989). A general model for fuzzy linear programming. Fuzzy Sets and systems, 29(1), 21-29.

De Boer, L., Labro, E., \&Morlacchi, P. (2001). A review of methods supporting supplier selection. European journal of purchasing \& supply management, 7(2), 75-89.

Demirtas, E. A., \&Ustun, O. (2009). Analytic network process and multi-period goal programming integration in purchasing decisions. Computers \& Industrial Engineering, 56(2), 677-690.

Drexl, A., \&Kimms, A. (1997). Lot sizing and scheduling-survey and extensions. European Journal of operational research, 99(2), 221-235.

Dubois, D., Fargier, H., \&Fortemps, P. (2003). Fuzzy scheduling: Modelling flexible constraints vs. coping with incomplete knowledge. European Journal of Operational Research, 147(2), 231-252.

Fan, J., \& Wang, G. (2018). Joint optimization of dynamic lot and warehouse sizing problems. European Journal of Operational Research, 267(3), 849-854.

Fan, Z., Li, S., \& Gao, Z. (2019). Multiobjective Sustainable Order Allocation Problem Optimization with Improved Genetic Algorithm Using Priority Encoding. Mathematical Problems in Engineering, 2019.

Ehrgott, M. (2005). Multicriteria optimization (Vol. 491). Springer Science \& Business Media.

Engau, A., \&Wiecek, M. M. (2007). Generating $\varepsilon$-efficient solutions in multi objective programming. European Journal of Operational Research, 177(3), 1566-1579.

Govindan, K., \& Sivakumar, R. (2016). Green supplier selection and order allocation in a low-carbon paper industry: integrated multi-criteria heterogeneous decision-making and multi-objective linear programming approaches. Annals of Operations Research, 238(1-2), 243-276. 
Gruson, M., Bazrafshan, M., Cordeau, J. F., \&Jans, R. (2019). A comparison of formulations for a threelevel lot sizing and replenishment problem with a distribution structure. Computers \& Operations Research, 111, 297-310.

Gupta, P., Govindan, K., Mehlawat, M. K., \& Kumar, S. (2016). A weighted possibilistic programming approach for sustainable vendor selection and order allocation in fuzzy environment. The International Journal of Advanced Manufacturing Technology, 86(5-8), 1785-1804.

Gupta, H., \&Barua, M. K. (2018). A framework to overcome barriers to green innovation in SMEs using BWM and Fuzzy TOPSIS. Science of The Total Environment, 633, 122-139.

Guua, S. M., \& Wu, Y. K. (1999). Two-phase approach for solving the fuzzy linear programming problems. Fuzzy Sets and Systems, 107(2), 191-195.

Hadley, G., \&Whitin, T. M. (1963). Analysis of inventory systems (No. 658.787 H3).

Harris, F.W., 1990. How many parts to make at once?. Operations Research 38 (6), 947-950 [Reprinted from Factory: The Magazine of Management 10(2), 1913, pp. 135-136].

Heck, M., \& Schmidt, G. (2010). Lot-size planning with non-linear cost functions supporting environmental sustainability. International Journal of Green Computing (IJGC), 1(1), 34-39.

Hendiani, S., Liao, H., Ren, R., \& Lev, B. (2020). A likelihood-based multi-criteria sustainable supplier selection approach with complex preference information. Information Sciences.

Humphreys, P. K., Wong, Y. K., \& Chan, F. T. S. (2003). Integrating environmental criteria into the supplier selection process. Journal of Materials processing technology, 138(1-3), 349-356.

Humphreys, P., McCloskey, A., McIvor, R., Maguire, L., \&Glackin, C. (2006). Employing dynamic fuzzy membership functions to assess environmental performance in the supplier selection process. International Journal of Production Research, 44(12), 2379-2419.

Hua, G., Cheng, T. C. E., \& Wang, S. (2011). Managing carbon footprints in inventory management. International Journal of Production Economics, 132(2), 178-185.

Hu, Z., \& Hu, G. (2020). Hybrid stochastic and robust optimization model for lot-sizing and scheduling problems under uncertainties. European Journal of Operational Research, 284(2), 485-497.

Hwang, C. L., \&Masud, A. S. M. (2012). Multiple objective decision making-methods and applications: a state-of-the-art survey (Vol. 164). Springer Science \& Business Media.

Hwang, C. L., \& Yoon, K. (1981). Methods for multiple attribute decision making. In Multiple attribute decision making (pp. 58-191). Springer, Berlin, Heidelberg. 
Inuiguchi, M., \&Ramık, J. (2000). Possibilistic linear programming: a brief review of fuzzy mathematical programming and a comparison with stochastic programming in portfolio selection problem. Fuzzy sets and systems, 111(1), 3-28.

Jain, N., \& Singh, A. R. (2020). Sustainable supplier selection under must-be criteria through Fuzzy inference system. Journal of Cleaner Production, 248, 119275.

Jans, R., \&Degraeve, Z. (2007). Meta-heuristics for dynamic lot sizing: A review and comparison of solution approaches. European journal of operational research, 177(3), 1855-1875.

Jia, R., Liu, Y., \& Bai, X. (2020). Sustainable supplier selection and order allocation: Distributionally robust goal programming model and tractable approximation. Computers \& Industrial Engineering, 140, 106267.

Jiménez, M., Arenas, M., Bilbao, A., \&Rodrı, M. V. (2007). Linear programming with fuzzy parameters: an interactive method resolution. European journal of operational research, 177(3), 1599-1609.

Kaur, H., \& Singh, S. P. (2017). Modeling low carbon procurement and logistics in supply chain: A key towards sustainable production. Sustainable Production and Consumption, 11, 5-17.

Kirschstein, T., \& Meisel, F. (2019). A multi-period multi-commodity lot-sizing problem with supplier selection, storage selection and discounts for the process industry. European Journal of Operational Research, 279(2), 393-406.

Karimi, B., Ghomi, S. F., \& Wilson, J. M. (2003). The capacitated lot sizing problem: a review of models and algorithms. Omega, 31(5), 365-378.

Kantas, A. B., Cobuloglu, H. I., \&Büyüktahtakın, İ. E. (2015). Multi-source capacitated lot-sizing for economically viable and clean biofuel production. Journal of Cleaner Production, 94, 116-129.

Kabak, Ö., \&Ülengin, F. (2011). Possibilistic linear-programming approach for supply chain networking decisions. European Journal of Operational Research, 209(3), 253-264.

Kang, K., Pu, W., Ma, Y., \& Wang, X. (2018). Bi-objective inventory allocation planning problem with supplier selection and carbon trading under uncertainty. PloS one, 13(11), e0206282.

Kaur, H., \& Singh, S. P. (2019). Flexible dynamic sustainable procurement model. Annals of Operations Research, 273(1-2), 651-691.

Keshavarz Ghorabaee, M., Amiri, M., \&Turskis, Z. (2017). A new approach for solving bi-objective redundancy allocation problem using DOE, simulation and $\varepsilon$-constraint method. Informatica, 28(1), 79-104. 
Lahri, V., Shaw, K., \& Ishizaka, A. (2020). Sustainable Supply chain network design problem: using the integrated BWM, TOPSIS, possibilistic programming, and e-constrained methods. Expert Systems with Applications, 114373.

Lahri, V. (2020). Assessment of critical drivers towards sustainable green supply chain performance management. International Journal of Business Performance and Supply Chain Modelling, 11(3), 228-251.

Lai, Y. J., \& Hwang, C. L. (1992). A new approach to some possibilistic linear programming problems. Fuzzy sets and systems, 49(2), 121-133.

Lai, Y. J., \& Hwang, C. L. (1993). Possibilistic linear programming for managing interest rate risk. Fuzzy Sets and Systems, 54(2), 135-146.

Liu, Z., \& Stephens, V. (2019). Exploring innovation ecosystem from the perspective of sustainability: Towards a conceptual framework. Journal of Open Innovation: Technology, Market, and Complexity, 5(3), 48.

Liang, T. F. (2006). Distribution planning decisions using interactive fuzzy multi-objective linear programming. Fuzzy Sets and Systems, 157(10), 1303-1316.

Li, X. Q., Zhang, B., \& Li, H. (2006). Computing efficient solutions to fuzzy multiple objective linear programming problems. Fuzzy sets and systems, 157(10), 1328-1332.

Lamba, K., Singh, S. P., \& Mishra, N. (2019). Integrated decisions for supplier selection and lot-sizing considering different carbon emission regulations in Big Data environment. Computers \& Industrial Engineering, 128, 1052-1062.

Maes, J., \& Van Wassenhove, L. (1988). Multi-item single-level capacitated dynamic lot-sizing heuristics: A general review. Journal of the Operational Research Society, 39(11), 991-1004.

Mani, V., Agrawal, R., \& Sharma, V. (2014). Supplier selection using social sustainability: AHP based approach in India. International Strategic Management Review, 2(2), 98-112.

Memari, A., Dargi, A., Jokar, M. R. A., Ahmad, R., \& Rahim, A. R. A. (2019). Sustainable supplier selection: A multi-criteria intuitionistic fuzzy TOPSIS method. Journal of Manufacturing Systems, 50, 9-24.

Min, H., \& Galle, W. P. (1997). Green purchasing strategies: trends and implications. International Journal of Purchasing and Materials Management, 33(2), 10-17. 
Mohammadi, M., Esmaelian, M., \&Atighehchian, A. (2020). Design of mathematical models for the integration of purchase and production lot-sizing and scheduling problems under demand uncertainty. Applied Mathematical Modelling.

Mohammed, A., Harris, I., \& Govindan, K. (2019). A hybrid MCDM-FMOO approach for sustainable supplier selection and order allocation. International Journal of Production Economics, 217, 171184.

Mula, J., Poler, R., \& Garcia, J. P. (2006). MRP with flexible constraints: A fuzzy mathematical programming approach. Fuzzy sets and systems, 157(1), 74-97.

Önal, M., \&Romeijn, H. E. (2010). Multi- item capacitated lot- sizing problems with setup times and pricing decisions. Naval Research Logistics (NRL), 57(2), 172-187.

Parra, M. A., Terol, A. B., Gladish, B. P., \&Urıa, M. R. (2005). Solving a multiobjective possibilistic problem through compromise programming. European Journal of Operational Research, 164(3), 748-759.

PAS 2050., 2011. Specification for the assessment of the life cycle greenhouse gas emissions of goods and services. $\quad$ Downloaded from: http://www.bsigroup.com/upload/Standards\%20\&\%20Publications/Energy/PAS2050.pdf

Pathak, U., Kant, R., \& Shankar, R. (2020). Analytics of cap-and-trade policy for dual supply chain network structures. Clean Technologies and Environmental Policy, 22(10), 1999-2021.

Phouratsamay, S. L., \& Cheng, T. C. E. (2019). The single-item lot-sizing problem with two production modes, inventory bounds, and periodic carbon emissions capacity. Operations Research Letters, 47(5), 339-343.

Pishvaee, M. S., \&Razmi, J. (2012). Environmental supply chain network design using multi-objective fuzzy mathematical programming. Applied Mathematical Modelling, 36(8), 3433-3446.

Pishvaee, M. S., \&Torabi, S. A. (2010). A possibilistic programming approach for closed-loop supply chain network design under uncertainty. Fuzzy sets and systems, 161(20), 2668-2683.

Quezada, F., Gicquel, C., Kedad-Sidhoum, S., \& Vu, D. Q. (2020). A multi-stage stochastic integer programming approach for a multi-echelon lot-sizing problem with returns and lost sales. Computers \& Operations Research, 116, 104865. 
Razmi, J., \&Maghool, E. (2010). Multi-item supplier selection and lot-sizing planning under multiple price discounts using augmented $\varepsilon$-constraint and Tchebycheff method. The International Journal of Advanced Manufacturing Technology, 49(1-4), 379-392.

Rezaei, J. (2015). Best-worst multi-criteria decision-making method. Omega, 53, 49-57.

Rezaei, J. (2016). Best-worst multi-criteria decision-making method: Some properties and a linear model. Omega, 64, 126-130.

Rezaei, J., \&Davoodi, M. (2011). Multi-objective models for lot-sizing with supplier selection. International Journal of Production Economics, 130(1), 77-86.

Robinson, P., Narayanan, A., \&Sahin, F. (2009). Coordinated deterministic dynamic demand lot-sizing problem: A review of models and algorithms. Omega, 37(1), 3-15.

Sakawa, M., Yano, H., \&Yumine, T. (1987). An interactive fuzzy satisficing method for multiobjective linear-programming problems and its application. IEEE Transactions on Systems, Man, and Cybernetics, 17(4), 654-661.

Sancak, E., \& Salman, F. S. (2011). Multi-item dynamic lot-sizing with delayed transportation policy. International Journal of Production Economics, 131(2), 595-603.

Şenyiğit, E. R. C. A. N., \& Erol, R. I. Z. V. A. N. (2010). New lot sizing heuristics for demand and price uncertainties with service-level constraint. International Journal of Production Research, 48(1), 21-44.

Selim, H., \&Ozkarahan, I. (2008). A supply chain distribution network design model: an interactive fuzzy goal programming-based solution approach. The International Journal of Advanced Manufacturing Technology, 36(3-4), 401-418.

Sharma, R. K., Singh, P. K., Sarkar, P., \& Singh, H. (2020). A hybrid multi-criteria decision approach to analyze key factors affecting sustainability in supply chain networks of manufacturing organizations. Clean Technologies and Environmental Policy, 22(9), 1871-1889.

Shaw, K. (2017). Fuzzy multi-objective, multi-item, multi-supplier, lot-sizing considering carbon footprint. International Journal of Mathematics in Operational Research, 11(2), 171-203.

Sikdar, S. K., Sengupta, D., \& Mukherjee, R. (2017). Energy Sustainability, Water Sustainability. In Measuring Progress Towards Sustainability (pp. 221-273). Springer, Cham.

Sikdar, S. K. (2007). Sustainability and recycle-reuse in process systems. Clean Technologies and Environmental Policy, 9(3), 167-174. 
Sikdar, S. K., Sengupta, D., \& Mukherjee, R. (2017). Measuring progress towards sustainability. Springer International Publishing. doi, 10, 978-3.

Slama, I., Ben-Ammar, O., Dolgui, A., \&Masmoudi, F. (2020). New mixed integer approach to solve a multi-level capacitated disassembly lot-sizing problem with defective items and backlogging. Journal of Manufacturing Systems, 56, 50-57.

Staniškienè, E., \&Stankevičiūtè, Ž. (2018). Social sustainability measurement framework: The case of employee perspective in a CSR-committed organisation. Journal of cleaner production, 188, 708719.

Tanaka, H., \&Asai, K. (1984). Fuzzy linear programming problems with fuzzy numbers. Fuzzy sets and systems, 13(1), 1-10.

Tiwari, R. N., Dharmar, S., \& Rao, J. (1987). Fuzzy goal programming — an additive model. Fuzzy sets and systems, 24(1), 27-34.

Torabi, S. A., \&Hassini, E. (2008). An interactive possibilistic programming approach for multiple objective supply chain master planning. Fuzzy sets and systems, 159(2), 193-214.

Tosarkani, B. M., \& Amin, S. H. (2018). A possibilistic solution to configure a battery closed-loop supply chain: multi-objective approach. Expert Systems with Applications, 92, 12-26.

Ustun, O., \&Demirtas, E. A. (2008). Multi-period lot-sizing with supplier selection using achievement scalarizing functions. Computers \& Industrial Engineering, 54(4), 918-931.

Vaez, P., Sabouhi, F., \&Jabalameli, M. S. (2019). Sustainability in a lot-sizing and scheduling problem with delivery time window and sequence-dependent setup cost consideration. Sustainable Cities and Society, 51, 101718.1

van Norden, L., \& van de Velde, S. (2005). Multi-product lot-sizing with a transportation capacity reservation contract. European Journal of Operational Research, 165(1), 127-138.

Venkatesh, V. G., Zhang, A., Deakins, E., \& Mani, V. (2020). Drivers of sub-supplier social sustainability compliance: an emerging economy perspective. Supply Chain Management: An International Journal.

Wagner, H. M., \&Whitin, T. M. (1958). Dynamic version of the economic lot size model. Management science, 5(1), 89-96.

Whitin, T.M., 1953. The Theory of Inventory Management. Princeton University Press, Princeton, NJ. 
Winter, S., \&Lasch, R. (2016). Environmental and social criteria in supplier evaluation-Lessons from the fashion and apparel industry. Journal of Cleaner Production, 139, 175-190.

Wu, T., \& Shi, L. (2011). Mathematical models for capacitated multi-level production planning problems with linked lot sizes. International Journal of Production Research, 49(20), 6227-6247.

Wu, T., Xiao, F., Zhang, C., He, Y., \& Liang, Z. (2018). The green capacitated multi-item lot sizing problem with parallel machines. Computers \& Operations Research, 98, 149-164.

You, S. Y., Zhang, L. J., Xu, X. G., \& Liu, H. C. (2020). A New Integrated Multi-Criteria Decision Making and Multi-Objective Programming Model for Sustainable Supplier Selection and Order Allocation. Symmetry, 12(2), 302.

You, P., Guo, S., Zhao, H., \& Zhao, H. (2017). Operation performance evaluation of power grid enterprise using a hybrid BWM-TOPSIS method. Sustainability, 9(12), 2329.

Yu, C., Shao, Y., Wang, K., \& Zhang, L. (2019). A group decision making sustainable supplier selection approach using extended TOPSIS under interval-valued Pythagorean fuzzy environment. Expert Systems with Applications, 121, 1-17.

Zhou, S., Zhou, Y., Zuo, X., Xiao, Y., \& Cheng, Y. (2018). Modeling and solving the constrained multiitems lot-sizing problem with time-varying setup cost. Chaos, Solitons \& Fractals, 116, 202-207.

Zimmermann, H. J. (1978). Fuzzy programming and linear programming with several objective functions. Fuzzy sets and systems, 1(1), 45-55.

\section{[INSERT APPENDIX A]}




\section{Credit Author Statement}

\section{Krishnendu Shaw:}

Model development, Code correction, and development, Writing - Review \& Editing, Results validation.

Vijay Lahri:

Conceptualization, Model development, Methodology, Writing-draft preparation, Data analysis.

\section{Ravi Shankar:}

Review, Language editing.

\section{Declaration of interests}

The authors declare that they have no known competing financial interests or personal relationships that could have appeared to influence the work reported in this paper. 


\section{Figures}

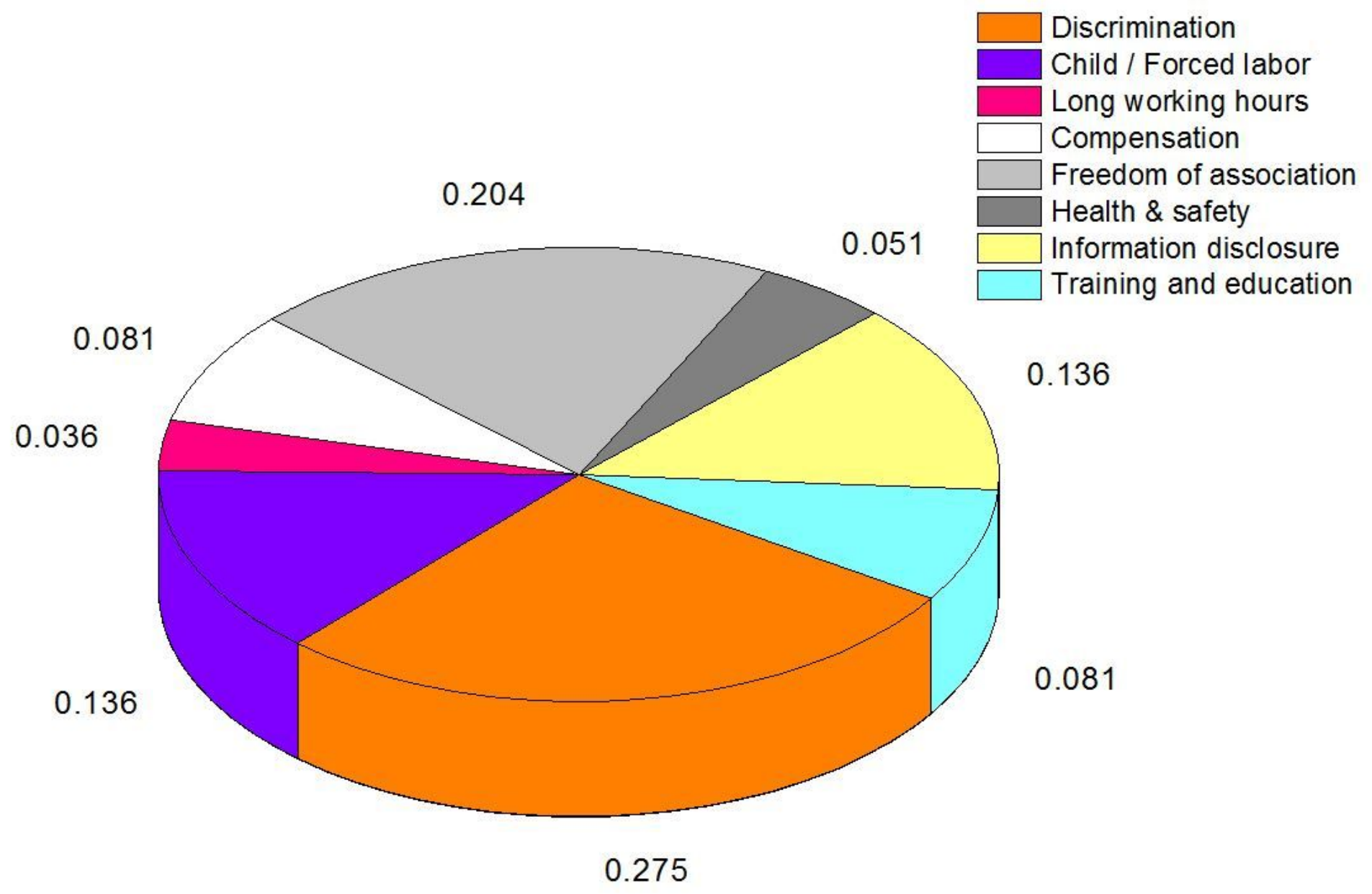

Figure 1

Weights of supplier's social criteria 


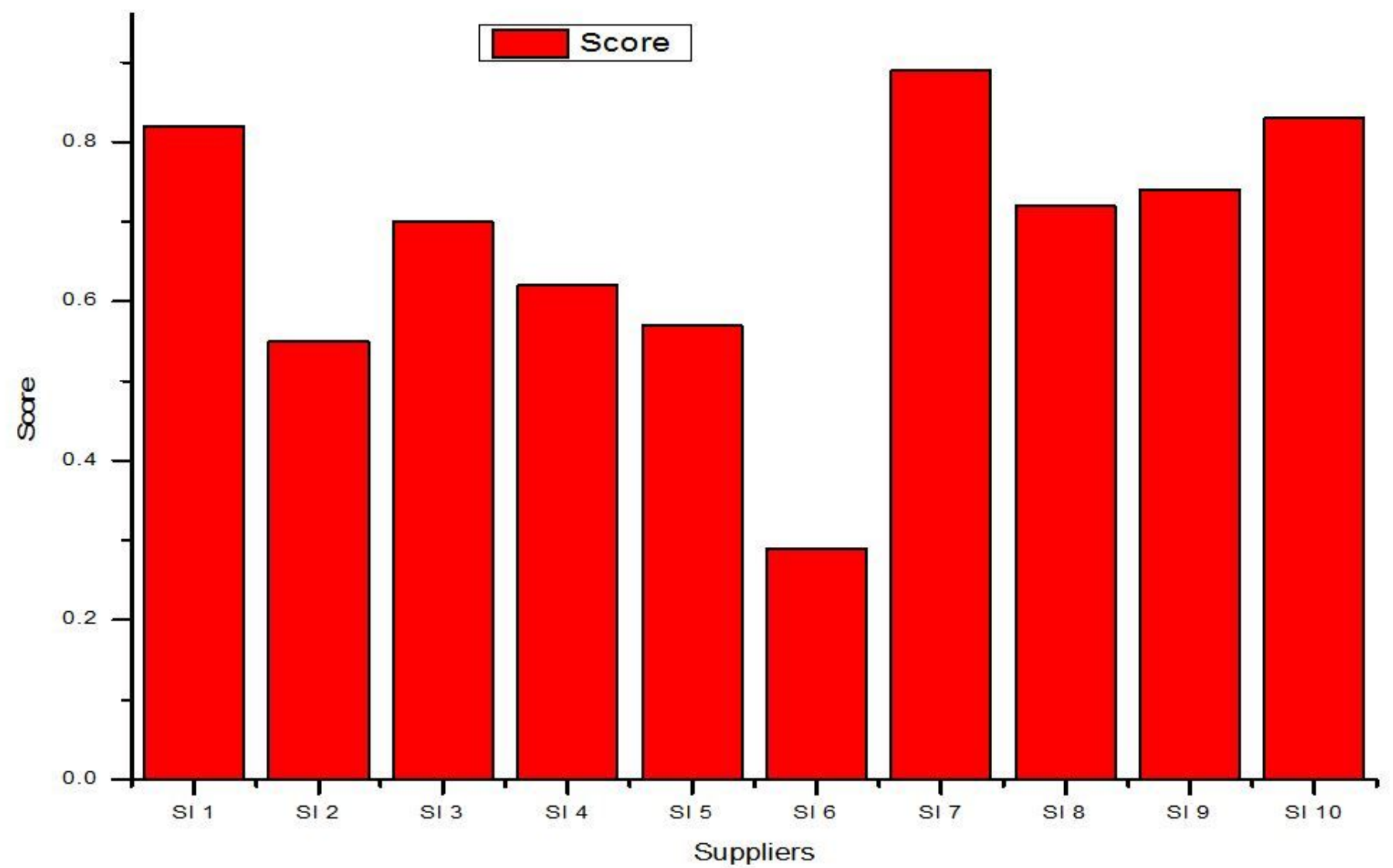

Figure 2

Ranking of potential sustainable suppliers 

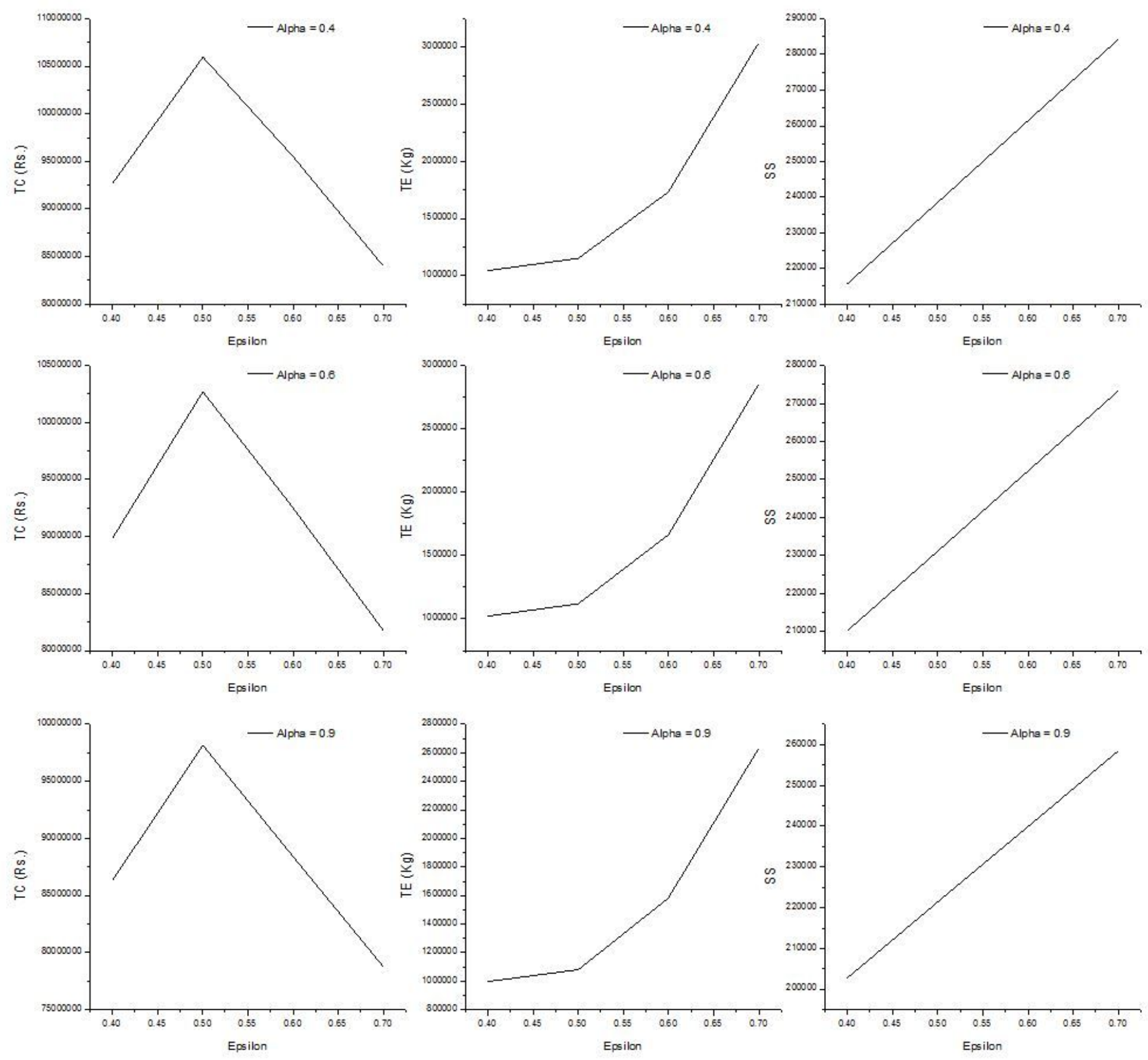

\section{Figure 3}

Sensitivity analysis of TC, TE, and SS by changing $\varepsilon$ value at distinct a setting. 

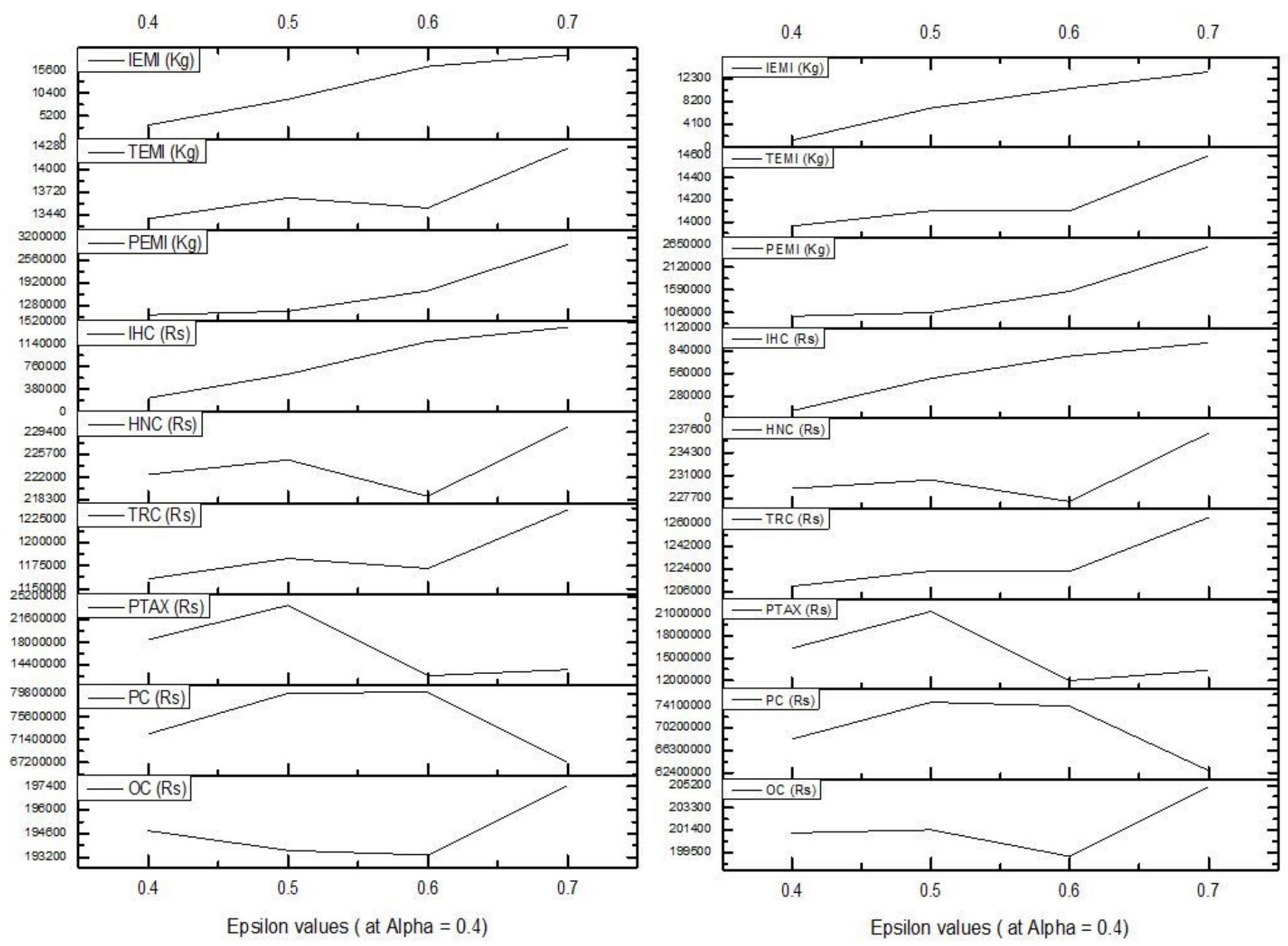

Figure 4

Sensitivity analysis cost and emission parameters by changing $\varepsilon$ value at different a values.

\section{Supplementary Files}

This is a list of supplementary files associated with this preprint. Click to download.

- appendixA.docx 